Portland State University

PDXScholar

1983

\title{
Adult oral diadochokinesis rates : preliminary normative data
}

Carol Kafton-Minkel

Portland State University

Follow this and additional works at: https://pdxscholar.library.pdx.edu/open_access_etds

Part of the Physiology Commons, and the Speech Pathology and Audiology Commons Let us know how access to this document benefits you.

\section{Recommended Citation}

Kafton-Minkel, Carol, "Adult oral diadochokinesis rates : preliminary normative data" (1983). Dissertations and Theses. Paper 3339.

https://doi.org/10.15760/etd.5232

This Thesis is brought to you for free and open access. It has been accepted for inclusion in Dissertations and Theses by an authorized administrator of PDXScholar. Please contact us if we can make this document more accessible: pdxscholar@pdx.edu. 
AN ABSTRACT OF THE THESIS OF Carol Kafton-Minkel for the Master of Science in Speech Communication, with an emphasis in Speech-Language Pathology, presented March 8, 1983.

Title: Adult Oral Diadochokinesis Rates: Preliminary Normative Data. APPROVED BY MEMBERS OF THE THESIS COMMITTEE:

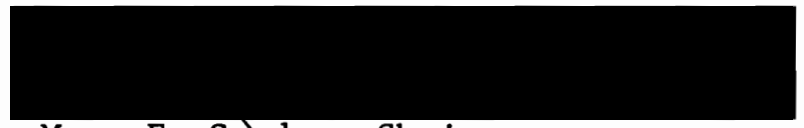

Mary E. Gordon, Chairperson

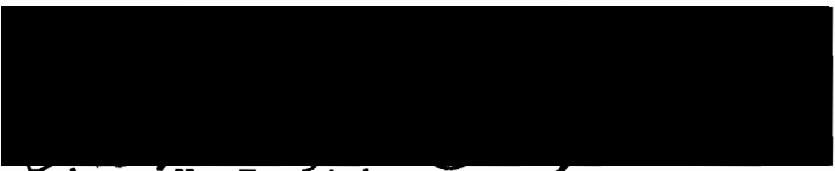

Řobert H. English

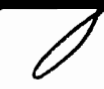

In the clinical evaluation and management of speech disorders, a speech-language pathologist may observe disturbances in a client's motor abilities that suggest possible neurological dysfunction. One possible disturbance is in oral diadochokinesis (DIO), an individual's ability to start and stop the movement of the articulators rapidly and execute repetitive, alternating, sequential movements typically associated with speech articulation. It is often recommended that a speech-language pathologist test DIO speed and compare the performance to available norms. 
There is, however, a lack of normative DIO data spanning all ages of adulthood. The purpose of this study was to develop preliminary normative data on the speed of oral diadochokinesis used in articulation of syllables and oral movements by adults. The investigation sought to answer the question: What are the mean rates of oral diadochokinetic syllable productions and selected oral movements for each decade of adulthood?

Eighty-four subjects participated in this study, six men and six women from each decade of adulthood, beginning with the decade twenty to twenty-nine and ending with eighty and older. Subjects displayed no observable neurologies or articulation errors, and they reported no history of neurological impairment, ill-fitting dentures, respiratory disorders, or recent ingestion of speed-affecting drugs.

Subjects were instructed to repeat at least twenty productions of $|\mathrm{p} \wedge /,| \mathrm{t} \wedge /$, and $/ \mathrm{k} \wedge /$, fifteen productions of $/ \mathrm{p} \wedge t \theta /, / \mathrm{p} \wedge \mathrm{k} \partial /$, and $/ \mathrm{t} \wedge \partial /$, ten productions of /pntako/ and twenty teeth clicks and lip bounces as quickly as possible. They repeated each series of syllables or movements three times. The movements were counted and timed on the spot, while the syllables were tape recorded. The tape was played back at half speed, the productions were counted, timed and calculated into means and standard deviations for each decade.

Results of this study revealed a slight tendency toward decreased DIO speed as age increases, although the speed of the fastest decade for five tasks was within one standard deviation of the speed of the slowest decade and within two standard deviations for the other four tasks. Sounds produced at the front of the mouth also were observed to be faster than those produced at the back of the mouth. 
Data were collected on the speed of males and females. Men and women performed at approximately equal speeds in the twenties, thirties, and eighties. Men in their forties, fifties, and seventies were faster than the matched women, while women in their sixties were faster than the men. 
ADULT ORAL DIADOCHOKINESIS RATES:

PRELIMINARY NORMATIVE DATA

by

CAROL KAFTON-MINKEL

A thesis submitted in partial fulfillment of the requirements for the degree of

MASTER OF SCIENCE IN SPEECH COMMUNICATION:

with an emphasis in

SPEECH-LANGUAGE PATHOLOGY/AUDIOLOGY

Portland State University 
TO THE OFFICE OF GRADUATE STUDIES AND RESEARCH:

The members of the Committee approve the thesis of Carol KaftonMinkel presented March 8, 1983.
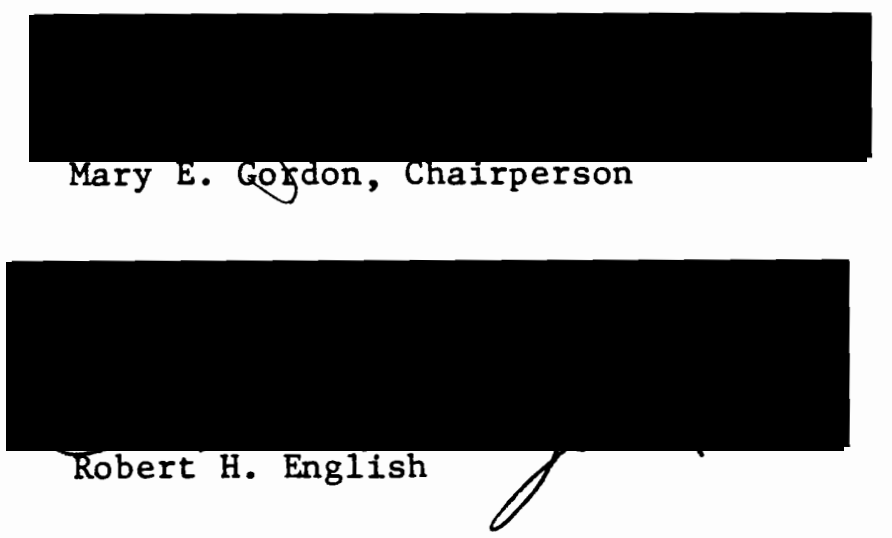

APPROVED :

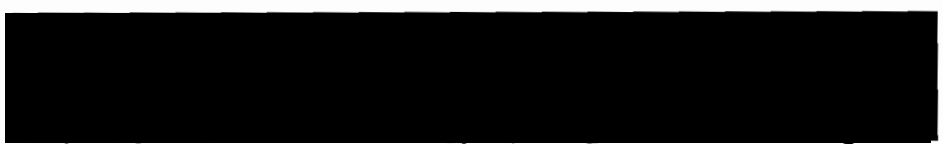

Theodore G. Grove, Chair, Department of

Speech Communication

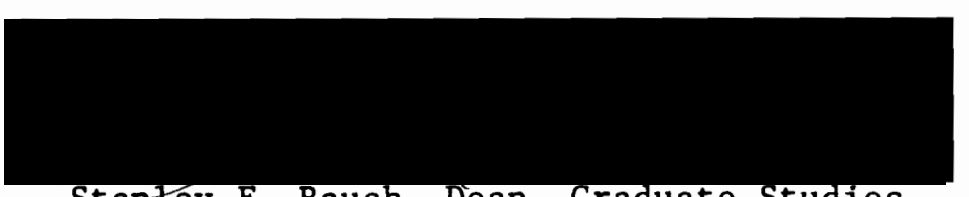

Stanley E. Rauch, Dean, Graduate Studies

and Research 


\section{ACKNOWLEDGEMENTS}

I wish to acknowledge the participation and help from many people in the completion of this study:

Mary Gordon, for her advice and thesis direction, Robert English, for his guidance,

Linda Neklason, for her orals participation, Allen Clark, for information on dentures, Les Schmertzler, for medical information, Marilyn Caum, for flying fingers and sharp eyes, All subjects, both in Salinas and Portland, Diana Schneider and Cathy Thompson, for "calibrating" me, Lori Hickman, Cathy Thompson and Renee Chambers, for providing a support system,

Harold and Shirley Kafton, for encouragement and subject searching, and

Walter Kafton-Minkel, for typing, editing, support and love. 
ACKNOWLEDGEMENTS ................... LIST OF TABLES ..................... v v

\section{CHAPTER}

I INTRODUCTION

Statement of Purpose . . . . . . . . . . . . 3

II REVIEW OF THE LITERATURE

Past Studies of Oral DIO Using Normal Speakers . . . 5

A Composite View of Past DIO Studies . . . . . . . 13

Methods of DIO Rate Collection . . . . . . . . 16

Factors Influencing DIO Rate ........... 20

Summary . . . . . . . . . . . . . . . 21

III METHODS AND PROCEDURES $\quad 22$

Subjects •. • • • . • . . . . . • . . . . 22

Equipment ..................... 22

Setting ..................... . 22

Examiner Reliability . . . . . . . . . . . 23

Sounds and Movements Tested . . . . . . . . . 23

Method of Measuring Data . . . . . . . . . 24

Procedure .. . . . . . . . . . . . . 24

Data Measurement and Analysis . . . . . . . 26

$\begin{array}{ll}\text { IV RESULTS AND DISCUSSION } & 27\end{array}$

Results •. . . . . . . . . . . . . . 27

Discussion ................... 32

V SUMMARY AND IMPLICATIONS

Summary . . . . . . . . . . . . . 35

Implications . . . . . . . . . . . . . . 36

$\begin{array}{ll}\text { SELECTED BIBLIOGRAPHY } & 39\end{array}$

$\begin{array}{ll}\text { APPENDICES } & 42\end{array}$ 


\section{LIST OF TABLES}

TABLE

Page

I Preliminary Norms by Age . . . . . . . . . . . . 28

II Preliminary Norms by Sex: Men . . . . . . . . . . 30

III Preliminary Norms by Sex: Women . . . . . . . . . • 31 
CHAPTER I

\section{INTRODUCTION}

Diadochokinesis, the speed of rapid alternating movements, has long been employed as a diagnostic tool in speech-language pathology. Oral diadochokinesis (DIO) refers to an individual's ability to start and stop the movement of the articulators rapidly and execute repetitive, alternating, sequential movements typically associated with speech articulation (Johnson, 1980). Articulation requires extremely fine neuromotor adjustments to control the complex movement patterns and precision in strength, range, timing, and speed of muscular activity (Darley, Aronson, and Brown, 1975; Johnson, 1980). In assessing articulation skills, it is useful to break the speech process into its components to evaluate each operation separately. A common method of assessing the neuromotor adjustments needed for articulation, both clinically and experimentally, has been through the measurement of DIo rates (Johnson, 1980).

Normal articulation is dependent upon normal neuromotor functioning. The individual who can negotiate rapid shifts in the neuromotor adjustments of alternating movements during articulation generally possesses a high DIO rate (West, Ansberry, and Carr, 1957). Most people have a smooth, rapid pattern of alternating muscular movements. Others have hesitant and broken patterns of DIO.

Johnson (1980) believes DIO performance is related to articulation ability in certain populations, and that a display of poor DIO ability 
reflects deficits in neuromotor coordination. Weakness and slowness of movement are common symptoms of motor dysfunction and comprise about half of the complaints of patients with motor disabilities of neurologic origin (Darley et al., 1975). A report of the Mayo Clinic (1964) indicated a decrease in DIO rate may be a manifestation of cerebellar disease. Fletcher (1978) concurs that the rapid, rhythmic execution of complex motions, such as those in speech, can be profoundly influenced by diseases of the central nervous system. He notes disorders of the basal ganglia and cerebellum particularly influence articulation ability, thus, affecting DIO rate.

The cerebellum is primarily concerned with the coordination of motor activity, enabling complex movements which involve complex muscle groups. This coordination allows alternating movements to take place in a smooth, precise fashion (Mayo Clinic, 1964). The symptoms of cerebellar disease are disturbances of muscular coordination and locomotion. Voluntary movement is impaired; there is a delay in both initiating and relaxing muscle contraction. Alternating movements are carried out either slowly or irregularly and clumsily (De Jong, 1967). Darley et al. (1975) concur that the discrete and repetitive movements of articulation and DIO will be performed somewhat slowly and irregularly with the presence of cerebellar disease.

Johnson (1980) suggests both articulation error types and the severity of those errors may be differentially related to varying degrees of DIO impairment. Wertz (1978) believes some speech neuropathologies require a motor speech evaluation to detect their presence and severity. One suggested speech evaluation task is the rapid repeated production of syllables, such as /p^takə/. Johnson (1980) also suggests using the 
speed of syllable production as an index of DIO ability. Thus, DIO rates have been employed by speech-language pathologists to aid in differentially diagnosing neuromotor disorders involving articulation, and in determining the severity of neurological involvement.

A speech-language pathologist may observe disturbances in a client's motor abilities that suggest possible neurological dysfunction. Emerick and Hatten (1974) propose comparing various facets of the client's motor performance with norms corresponding to his age level. It is difficult for the speech-language pathologist to compare data on an assessment of adults, however, because there is a lack of adult normative DIO data. Hutchinson, Hanson, and Mecham (1979) state, "During the early decades of speech pathology research there was an interest in ascertaining the average ranges of structure and function for speech, but the interest waned before complete normative data were established." A collection of DIO data over a wide age range of adults is valuable because, as Birren (1956) writes, "A systematic study of age changes in speed of responses and timing appears to be one of the most advantageous ways of exploring the nature of age changes in behavior and the aging nervous system." Ptacek, Sander, Maloney, and Jackson (1966) further caution that greater care must be taken when normative data, based on a younger adult population, are used in assessing the factors subserving speech of older age groups. Therefore, DIO rate norms are needed for assessing adults of all ages.

\section{Statement of Purpose}

The purpose of this study was to develop preliminary normative data on the speed of oral diadochokinesis used in articulation of 
syllables and oral motor movements by adults. More specifically, this study will be concerned with adults in each decade of life from twenty through eighty and older years.

The question this investigation sought to answer was:

What are the mean rates of diadochokinetic syllable production and of selected oral movements for each decade of adulthood? 


\section{CHAPTER II}

\section{REVIEW OF THE LITERATURE}

A number of DIO studies related to speech-language pathology have been conducted since Pettit (1939) and Schlanger (1939) presented data on the speed of jaw movement among children and its relationship to stuttering. In this chapter, the comparative aspects of normative DIO studies will be reviewed. More specifically, consideration will be given to the purposes and findings of each DIO study, the age groups studied, sounds or movements examined, equipment and timing methods used, and a summary of the speed of DIO as a function of age among normal speakers. A description of some factors affecting the production of normal DIO also will be discussed.

\section{Past Studies of Oral DIO Using Normal Speakers}

Speech researchers have sought to obtain normative DIO data on many age groups and for a variety of purposes. Their studies have employed a wide range of alternating movements such as finger tapping, mandibular opening and closing, and repetition of various syllables. Most research, thus far, has been conducted with children aged six through seventeen. Although some studies have dealt with adults, only two have involved a geratric population. Early DIO research compared stutterers to nonstutterers; later research compared those with good articulation and impaired articulation.

Both Schlanger (1939) and Pettit (1939) established normative data 
on the opening and closing of the jaw by children. Schlanger obtained DIO rates from 109 children, aged seven, eight, and nine, to establish normative data, and to compare performances by age and sex. Pettit's goals were the same, although he studied the jaw movement rates of twelve- through seventeen-year-olds. Subjects for both studies were in equal numbers, boys to girls. The combined results of the Schlanger and Pettit studies indicate there is a progressive rise in the speed of jaw opening and closing; i.e., the older the child, the faster the rate of movement. Girls across the ages tended to be faster than boys, although not to a statistically significant degree.

Jenkins (1941) intended to ". . complete the table of norms" started by Schlanger (1939) and Pettit (1939) on normative DI0 rates for opening and closing the jaw. Subjects consisted of 224 individuals at three age levels: 105 at the ten- to eleven-year level; 43 at the eighte en-year level; and 76 at the twenty-year level. There was a sex balance among subjects of all ages. The major conclusions Jenkins drew from the study were: 1) there seemed to be an increase in DIO rate of the jaw from the age of seven to the age of eighteen, then no age/rate correlation for the older subjects; 2) there seemed to be greater differences between the ages than the sexes; and 3) the standard deviations for males in each age group were greater than for females.

DIO rates for jaw, lip, and tongue movement to the alvealor ridge were obtained from 15 adult stutterers and 15 matched nonstutterers by Strother and Kriegman (1943). Age range for the nonstuttereres was eighteen to thirty-one years and nineteen to thirty-one for the stutterers. Strother and Kriegman sought to compare DIO rates on the three tasks of stutterers and nonstutterers. No statistically significant 
differences were found between the two groups on any of the tasks.

A battery of motor ability tasks, comparing 31 adult speakers with good articulation and 36 adult speakers with poor articulation, was administered by Albright (1948). Included were the DIO tasks of repeating the syllables $/ 1 \mathrm{a} /, / \mathrm{t} \wedge \mathrm{k} \theta /$, and $/ \mathrm{mu} /$, and production of repeated teeth clicks. Both groups, with a mean age of 19.6 years, were balanced as well as possible for sex. Statistically significant differences were found between the two groups on the syllable repetition tasks, with the good articulation group being faster. Although the poor articulation group was slower on the teeth clicks, the difference was determined not to be significant.

Blomquist's (1950) study was undertaken to establish mean DIO rates of repeated syllables for nine-, ten-, and eleven-year-old children. The 60 subjects were in equal numbers, boys to girls. Repeated syllables used were / pə/, / tə/, / kə/, and /pa ta kə/. Additionally, the study asked and answered four questions: 1) What is the relationship of DIO rate to age? Consistently, the older the child, the faster the speed on all sounds. 2) What is the relationship of DIO speed to sex? Although none of the differences were statistically significant, the boys were slightly faster than the girls in the same age group for all single syllables. The girls were faster on the trisyllable task. 3) How does practice affect DIO rate? There seemed to be a minor tendency for the first trial to be faster than the third, but not to a significant degree. 4) Does the speed of production differ for each sound? In all instances, production of $/ \mathrm{kg} /$ was the slowest.

The purpose of Lundeen's (1950) study was to investigate DIO rates in normal speaking adults. Subjects were 20 adult males with a mean age 
of twenty-eight and 20 females with a mean age of twenty-four, all with normal articulation. Ten consonant sounds were chosen for this investigation: $/ \mathrm{p} /, / \mathrm{b} /, / \mathrm{t} /,|\mathrm{d} /, / \mathrm{k} /,| \mathrm{g} /, \mid \mathrm{f} /, / \mathrm{v} /, / \mathrm{s} /$, and $/ z /$. These consonants were selected because they represented the voiced and voiceless cognates of five articulatory placements. Lundeen found the speed of repeated syllable production appeared to fall into three groups: the fastest was the 1ingua-alvealors and bilabials, /d/, /t/, /b/, and /p/; the labio-dentals /f/ and /v/ composed the next group; and the slowest group was the lingua-alvealors and 1 ingua-velars, $/ \mathrm{s} /, / \mathrm{z} /, / \mathrm{g} /$, and /k/. No significant differences were found between the voiced and voiceless cognates. A significant difference was found, however, between the sexes, with the males being faster. Additionally, Lundeen did a check/ recheck procedure with 2 subjects to determine if the order of syllable presentation made a difference in speed of production. There was no significant difference in either subject's rate of DIO.

Fairbanks and Spriestersbach (1950) investigated minor organic deviations, including DIO rates, in people with functional articulation disorders. Sixty students ranging in age from seventeen to twenty-four years participated in the study. Half the students were judged to have superior articulation while the other half were judged to have inferior articulation. Equal numbers of men and women were in each group. DIO tasks consisted of 1 ip and jaw movements, touching the tongue to the alvealor ridge, and tongue protrusion. Fairbanks and Spriestersbach found that differences between sex groups were consistently in favor of the male, but failed in statistical significance in most instances. They also noted only one comparison between articulation groups was significant; a male sex difference was obtained in favor of the superior 
articulation group on the lip movement task.

For their normative DIO rate study, Irwin and Becklund (1953) tested 130 boys and 130 girls aged six, seven, nine, eleven, thirteen, and fifteen, all with normal speech development. The repeated speech sounds used were $/ \mathrm{p} \partial /, / \mathrm{t} \partial /$, and $/ \mathrm{k} /$. These investigations attempted to determine the mean DIO rates of each age group and whether the mean rates increased withage. They concluded there is a small, somewhat uniform rate increase with age. Additionally, they noted although their research failed to demonstrate significant difference in speed between the sexes, younger boys tended to be slower than younger girls, while older boys tended to be faster than older girls.

Prins (1962) acquired normative DIO rate data on 71 normal speaking children, 41 girls and 30 boys, between the ages of three and seven years, with a mean age of five years. He compared these data to the DIO rates he acquired from 92 children with multiple articulation errors. The data were collected on repeated syllable productions of $/ \mathrm{p} \wedge /, / \mathrm{t} /$, $/ \mathrm{k} \wedge /, / \mathrm{p} \wedge t \wedge /$, and $/ \mathrm{p} \wedge t \wedge \mathrm{k} \wedge /$. Significant differences on DIO performances were found between the normal speaking and the articulation errored groups, with the normal speaking children performing faster.

DIO rates of repeated syllables /bo/, /do/, /go/, and /ha/ produced by 34 adults were recorded by Canter (1965). The subjects included 17 men with Parkinson's disease and a control group of 17 normal males. Both groups had a mean age of fifty-seven years. The study was designed to compare DIO rates of normal adult males with DIO rates of men with Parkinson's disease. The Parkinsonian group showed impaired ability to perform rapid movements of the tongue tip, back of the tongue, lips and vocal folds, when compared to the control group's performance. 
Ptacek et al. (1966) investigated certain speech changes, including DIO rates, associated with advancing age. The performances of two groups of subjects representing a normal, younger adult population and a normal, older adult population were studied. Both groups were somewhat balanced for sex. The 31 younger women ranged in age from eighteen to thirtyeight, with a mean age of twenty-four years; the age range for the 31 younger men was eighteen to thirty-eight, with a mean age of twentyeight. The older age group was composed of 27 men and 36 women. The men ranged in age from sixty-eight to eighty-nine years, with a mean age of seventy-seven; the women ranged from sixty-six to ninety-three years, with a mean age of seventy-seven. The DIO rate task was to repeat syllables $/ \mathrm{p} \wedge /, / \mathrm{t} N, \mid \mathrm{k} \wedge /, / \mathrm{p} \wedge t \wedge \mathrm{k}_{\wedge} /$, and $/ N$. DIO measurements were uniformly and significantly lower for the older than for the younger adult subjects. The older men were faster than the older women on all speech tasks. The younger men were faster than the younger women on the single syllable productions, yet slower on the multi-syllable productions.

The purpose of Weiss's (1968) investigation was to determine if the DIO rates of children with articulation disorders differed significantly from the DIO rates of children using normal articulation. Subjects were 40 eight-year-olds, including 10 boys and 10 girls with functional articulation disorders and a control group of 10 boys and 10 girls with normal speech. The subjects in the experimental group had from three to eight misarticulations. DIO rates were based on repetitions of $/ \mathrm{p} \wedge /, / \mathrm{nk} \partial /, / \mathrm{p} \wedge t \partial \mathrm{k} \partial /$, and teeth click. Maximum DIO rates for single syllable repetitions and teeth clicks showed insignificant differences between groups. The experimental group, however, was significantIy slower than the children with normal speech at repeating the 
multi-syllable tasks.

Fletcher (1972) conducted a study to generate normative data on DIO rates of children. Other objectives of this study were to compare DIO rate scores, based on age and sex, to determine if the order of presentation of the syllables affected performance, and to validate a newlydeveloped technique of DIO rate measuring. The following sounds were used: $/ \mathrm{p} \wedge /, / t_{\wedge} /, / \mathrm{k}_{\wedge} /, \mid \mathrm{f}_{\wedge} /, / 1 \wedge /, / \mathrm{p} \wedge t \partial /, / \mathrm{p} \wedge \mathrm{k} \partial /, / t_{\wedge} \mathrm{k} \partial /$, and $/ \mathrm{p} \wedge t \partial \mathrm{k} \partial /$. Fletcher (1972) selected these sounds to represent different levels of physiologic complexity based on a developmental pattern and articulatory placement. The randomly selected subjects were 24 boys and 24 girls at each age level between six and thirteen years, for a total of 384 children. A marked increase in the speed of production was found for each successive age except the six- to seven-year-olds. Only small differences were found between boys and girls in their DIO rate performances. In general, the girls tended to be somewhat faster than boys at younger ages and slower at older ages. Girls also tended to be faster at single-syllable repetitions, while boys were faster at multi-syllable repetitions. An analysis of variance according to the task order showed no significant differences for tasks placed in different orders in the test protocol. Although not reported in the study, Fletcher also obtained data on the non-speech acts of teeth click and lip bounce. The verbal production of syllables were to provide diagnostic information about the speech act, while the motor movements of teeth click and Iip bounce were to provide information on non-verbal oral motor involvement (English, 1982).

Kreul (1972) obtained DIO rates from three populations for the purpose of comparison. The three populations were: 1) 45 young normal adult college students, 20 males and 25 females, with a mean age of 
twenty-two years; 2) 22 normal older adults, 10 males and 12 females, with a mean age of seventy years; and 3) 23 individuals with Parkinson's disease with a mean age of fifty-six years. There was no balance for sex. Five syllables were utilized, $/ \mathrm{p} \wedge /, \mid \mathrm{t} \wedge /$, and $/ \mathrm{k} \wedge /$ (because they were believed to represent important articulatory movements made discretely enough to allow a count), the vowel /i/, and the vowel transition /u/ to /i/ (because the transition extended the representation of speech). The rates for $/ \mathrm{p} \wedge /, / \mathrm{t} \Lambda /$, and $/ \mathrm{k} / /$ showed no significant differences between the three groups of subjects. In the case of the interrupted vowel /i/, however, the subjects with Parkinsonism had significantly slower rates than the young and older normal adults; there was no difference between the young and older normals. Young males tended to perform faster than females; older females tended to perform faster than older males.

Sigurd (1973) investigated some of the restrictions of the human articulatory system. The primary purpose of this study was to examine the maximum repetition rate for open syllables of consonants or consonant blends followed by the vowel $/ a /$. Twenty-two consonant sounds and twentyeight blends were employed. The subjects were 8 men and 1 woman with a mean age of thirty years. The primary DIO findings of this study were the further back in the mouth the consonant originated, the slower the repetition, and there appeared to be an insignificant difference in production times of cognates, although the voiced cognate was slightly slower.

DIO rates of normal children were obtained by Canning and Rose (1974) for the purpose of providing norms and determining the accuracy of a proposed testing procedure (the time-by-count method) to be used in speech clinics. The subjects were 300 children in six age ranges, with 
25 boys and 25 girls in each age range. The first five groups covered the ages from four and a half to nine and a half years. The sixth group contained children aged thirteen and a half to fourteen and a half years. Six single consonant sounds, $/ \mathrm{t} /, / \mathrm{j} /, / \mathrm{k} /, / 1 /, / \mathrm{w} /$, and $/ \mathrm{p} /$, were chosen to represent the wide range of tongue and lip movements necessary for normal speech. The repeated sequence of $/ p, t, k /$ was also utilized. No significant differences between the sexes were found. Speed, however, significantly increased with age on all tasks.

Dworkin (1978) obtained DIO rates from an experimental group of 45 children with frontal $/ \mathrm{s} /$ and $/ z /$ and 45 children with normal articulation. The experimental group consisted of 21 males and 24 females, ranging in age from seven to twelve years with a mean age of eight years, nine months. Each control subject was paired with an experimental subject of the same sex and age within six months. Syllables used were repeated productions of $/ t_{\wedge} /,\left|d_{\Lambda} /,\right| k_{A} /$, and $/ g_{\wedge} /$. This investigation was designed to examine the relationship between DIO rates and the strength of lingual protrusion. The children with normal articulation repeated all syllables at a significantly faster rate than their experimental group counterparts.

\section{A Composite View of Past DIO Studies}

Findings on Sex Differences

Pettit (1939), Schlanger (1939), Irwin and Becklund (1953), Prins (1962), and Fletcher (1972) agree that young girls generally perform DIO tasks faster than young boys. 01der boys, however, were faster than older girls at the DIO tasks presented by Irwin and Becklund, Prins, and Fletcher. Fletcher found girls to be faster at single syllables and boys 
to be faster with multisyllables. The opposite conclusion was reached by Blomquist (1950).

Ptacek et al. (1966) found young adult women to be faster at multisyllable repetition than young adult men; the men were faster at single syllables. Lundeen (1950), Fairbanks and Spriestersbach (1950), and Kreul (1972) also found young adult males to perform faster than young adult females.

The results of Kreul (1972) and Ptacek at al. (1966) are conflicting. Kreul's older female subjects were faster than the older male subjects, while Ptacek et al. obtained results indicating older men to be faster than older women.

Findings on Speed of DIO in Relation to Age

Collectively, DIO rate studies of normal speakers indicate DIO rate increases with age during childhood, reaches a plateau in young adulthood, and decreases in older adulthood. Blomquist (1950), Irwin and Becklund (1953), Fletcher (1972), and Canning and Rose (1974) found production of the syllables $/ \mathrm{P} N /, / \mathrm{t} N /$, and $/ \mathrm{k} N /$ to increase in speed as age increased in children aged four and a half through fifteen. The studies of Pettit (1939), Schlanger (1939), and Jenkins (1941) also have indicated that the DIO rate of opening and closing the jaw increases with age in childhood. Jenkins' (1941) data reveal speed increases until about age eighteen. The jaw movement rates for ages seventeen through thirty-one presented by Strother and Kriegman (1943) and Fairbanks and Spriestersbach (1950) are in close agreement with the DIO rates of young adulthood reported by Jenkins (1941).

Ptacek et al. (1966) noted DIO measurements in their geriatric 
subjects (aged sixty-six to ninety-three) were uniformly lower than the scores of their young adult subjects. Kreul (1972) reported rates for $|\mathrm{p} \wedge /,| \mathrm{t} \wedge \mid$, and $/ \mathrm{k} \wedge /$ in his study did not differ significantly between the geriatric (aged sixty-five to seventy-six) and young adult (aged nineteen to twenty-eight) subjects; the discrepancy between the findings of these two studies, however, may be due to the seventeen-year difference between the oldest subjects in each study.

\section{$\underline{\text { A Continuum }}$}

If all the previously discussed studies were placed on an age continuum, enormous gaps would exist in the normative DIO data. Many ages have been scantily covered; other ages have not been addressed. The age group from thirty-nine through sixty-four is represented in only one previous study conducted by Canter (1965) who used seventeen subjects. These seventeen subjects had a median age of fifty-six years; no age range was provided. Ages having scant data are the thirties and adults older than seventy-six. Only one study (Ptacek et al., 1966) has been done using subjects in these age groups.

Another factor prevents formation of a complete continuum of normative DIO data--inconsistency in the syllables or movements used. Some researchers have tested DIO through jaw opening and closing; other researchers have utilized spoken syllables. Five researchers have looked only at movements. Five researchers obtained norms on cognates or syllables not used by other researchers. Seven studies involved various combinations of the syllables $/ \mathrm{p} \wedge /, / \mathrm{t} \wedge /$, and $/ \mathrm{k} \Lambda /$. Of those seven studies, however, some tested only single syllables, while others tested multi-sy11ables. 
The final factor preventing a formation of a continuum is the use of two different timing methods--count-by-time and time-by-count (see page 18 ). The rates reported by these two methods are so different that coordination of the data is impossible.

\section{Methods of DIO Rate Collection}

\section{Equipment Used}

Data collecting equipment employed in obtaining DIO rates for studies previously reported have been of three general types: visual representations of the DIO productions; auditory records of the DIO productions to be played back and analyzed at a later time; and combinations of the two. Some pieces of equipment were designed specifically for obtaining DIO rates, while others were common instruments adapted for DIO use. Sometimes a timing device was paired with the data collecting instrument.

Use of visual recording devices

A kymographic recording technique was employed by Pettit (1939) and Schlanger (1939). Both used a Marey recording tambour with an ink-writing stylus. The tambour was activated by pressure variations from a rubber tube placed in the subjects' mouths. As the subjects rapidly opened and closed their jaws, the writing point of the stylus moved in response, thus, visually recording the movement. Simultaneously, the stylus of a chronometer marked the time in seconds on a line a few inches below the DIO data line.

Strother and Kriegman (1943) utilized a Marey recording tambour attached to a polygraph to record movement of the jaw and lips. To detect jaw movements, a "sandwich" of two tongue blades and a rubber bulb 
was placed between the jaws. Lip movements were detected by placing a balloon tip between the teeth. This procedure kept the jaw fixed while the lip movements were recorded.

An electronic device was used by Fairbanks and Spriestersbach (1950) in recording DIO rates. The main component was a vacuum-tube relay unit, in which a relay was tripped when a high-resistance, low-amperage current was connected across the input terminals. The relay operated a counter which recorded every make-and-break. A section of the device was placed in the subject's mouth. Every movement caused a break in electrical curtent which activated a counter switch.

Irwin and Becklund (1953) employed an electro-acoustical instrument, a sound pulse meter or "sylrater," in establishing DIO normative data. The meter was sound-activated and the DIO rate was read from a modified voltmeter. Sigurd (1973) recorded syllable repetitions on an oscillograph, and Ptacek et al. (1966) used an oscillographic recorder.

Use of auditory recording devices

Albright (1948) recorded subjects' syllable repetitions on a diskrecording machine set at a normal speed. The productions were later played back at a slower speed to facilitate accurate recording.

Subjects in the Lundeen (1950) study recorded syllable productions on acetate disks. Simultaneously, a metronome set at one beat per second was recorded. This recording was played back at a slower speed later for analysis.

A tape recorder was utilized by Weiss (1968). Subjects were recorded at $71 / 2$ inches per second (IPS), and the repetitions were later played back at $33 / 4$ IPS for counting. Canning and Rose (1974) also used 
a tape recorder in conjunction with a stop watch for their study. Subjects in the Dworkin (1978) study were taped at $71 / 2$ IPS and played back at $33 / 4$ IPS for analysis. Dworkin utilized a stop watch for analysis.

Combined visual and auditory methods

Blomquist (1950) recorded subjects' syllable productions on a magnetic tape recorder. From the tape recordings, a visual image was produced on a sound spectrograph for counting.

Canter (1965) also made tape recordings as the subjects repeated syllables. These recordings were fed into a graphic level recorder for a visual printout.

Stop watch measurements of syllable repetitions were taken by Fletcher (1972) simultaneously with tape recordings. These recordings were later analyzed through an oscillographic printout for verification of timed rates.

All of the syllable repetitions were tape recorded in the Kreul (1972) study. The count was made by manually drawing the magnetic tape over a playback head. The recordings were also fed through a graphic level recorder to verify the count. Thus, both visual and auditory records were available.

\section{Timing Methods}

Two basic methods of timing repetitions for DIO norms have been utilized: count-by-time and time-by-count.

The count-by-time procedure requires the examiner to simultaneously perform two separate operations, one to measure time and the other to count repetitions within a pre-established time span. The result is a number of repetitions in the given time, e.8., twenty-eight repetitions 
of $/ \mathrm{p} \wedge /$ in five seconds.

With the time-by-count method, the number of repetitions is preestablished. A stop watch is started when the examiner begins to count the subject's repetitions. When the pre-established number is completed, the stop watch is halted, and the length of time can be recorded. The result is a certain amount of time to perform a given number of repetitions, e.g., 3.7 seconds to repeat $/ \mathrm{p} \wedge /$ twenty times.

\section{Count-by-time}

Many researchers have used the count-by-time method, but have reported the results in various ways. Schlanger (1939), Pettit (1939), Jenkins (1941), and Falrbanks and Spriestersbach (1950) reported data in the form of number of movements per second. The number of movements per three seconds is presented by Strother and Kriegman (1943) and Dworkin (1978).

Blomquist (1950), Lundeen (1950), Irwin and Becklund (1953), Canter (1965), Ptacek et al. (1966), Kreul (1972), and Sigurd (1973) reported their results as the number of syllables per second. Lundeen (1950) presented data on the number of syllables per five seconds, as did Prins (1962). The number of syllables per ten seconds was reported by Albright (1948).

\section{Time-by-count}

Three researchers have employed the time-by-count method developed by Fletcher in the early 1960's (English, 1982), Weiss (1968), Fletcher (1972), and Canning and Rose (1974). Weiss and Fletcher timed twenty repetitions of single syllables, fifteen repetitions of double syllables, and ten repetitions of triple syllables. Twenty repetitions of teeth 
clicks were also timed by Weiss and Fletcher. Canning and Rose timed ten repetitions of lateral tongue movements, single syllables, and triple syllables.

\section{Factors Influencing DIO Rate}

Numerous factors have been cited which influence performance on DIO tasks. These factors include: neurological or medical involvement, drugs, and dentures. The following is a description of these factors.

\section{Neurological Involvement or Medical Problems}

Poor performance on a DIO task may indicate neurological impairment (Rousey and Moriarty, 1965). Conversely, neurological impairment may affect performance on a DIO task. Muscular weakness or incoordination also may result in a slowed rate of alternating muscular contractions (Schmertzler, 1981). Schmertzler provided a list of illnesses which may affect DIO speed: stroke, Parkinson's disease, myasthenia gravis, cerebral palsy, multiple sclerosis, muscular dystrophy, history of uncontrolled seizures, a seizure in the previous forty-eight hours or any other illness or accident which at some time affected the speech process. Schmertzler further noted that medical problems such as emphysema or severe asthma may result in a slow DIO rate due to limited breath support.

\section{Drugs}

Drugs may have a major effect on motor performance (Schmertzler, 1981). Alcoholic beverages require one hour per ounce of pure alcohol to "clear" the human system, while minor tranquilizers (the diazepam and bidiazepam groups) require two days to clear the system (Schmertzler). Some brand names of minor tranquilizers are Librium and Valium 
(Physician's Desk Reference, 1980). The effects of major tranquilizers (the tricyclics group) and antipsychotics (the phenothiazines group) generally require an extended period of time to leave the human system (Schmertzler). Some brand names of major tranquilizers are Elavil and Haldo1. Three common brand names of antipsychotics are Thorazine, Compazine, and Stelazine (Physician's Desk Reference).

\section{Dentures}

Dentures do have an effect on speech, although Clark (1981) believes well-fitting dentures may affect articulatory precision rather than speed. Clark also noted lower dentures are more likely to cause speech problems than upper dentures, and partials cause the fewest problems. A person's own opinion of the effects of his/her dentures generally provides accurate information on his/her speech status.

\section{Summary}

From a review of the data on the previously mentioned studies, one concludes the normative information cannot be integrated on a continuum because ages have not been covered in a systematic manner, movements or sounds used differ in the various studies, and timing and reporting methods vary. Because testing of oral diadochokinesis is a commonly used diagnostic tool in speech-language pathology and a lack of cohesive normative DIO data exists, especially preliminary normative data on adult oral diadochokinesis using current clinical techniques. Speech-languge pathology references such as Weiss, Lillywhite, and Gordon (1980) recommend employing the time-by-count method and using syllables such as /p^/,

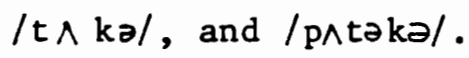


CHAPTER III

\section{METHODS AND PROCEDURES}

\section{Subjects}

Eighty-four healthy, normal, independently-living, subjects participated in this study, six men and six women from each decade of adulthood beginning with the decade of twenty to twenty-nine and ending with eighty and older. Subjects were selected from a population of people affiliated with Portland State University and from senior centers in the Portland, Oregon, metropolitan area, as well as members of a synagogue in Salinas, California. Subjects displayed no observable neurologies or articulation errors as judged by the investigator. Further, they reported no history of neurological impairment, ill-fitting or interfering dentures, severe respiratory disorders, or recent ingestion of speed-affecting drugs.

\section{Equipment}

A Sony reel-to-reel tape recorder, Realistic brand reel-to-reel recording tape, and a Seiko S002-5009 digital stop watch timed to one onehundredth of a second were used for data collection. Refer to Appendix A for the specifications for the tape recorder and tape.

\section{Setting}

The experimental setting was a quiet room in the subject's home, 
the examiner's home or an office at Portland State University. The subject was seated at a table at a right angle or across from the examiner. The tape recorder and microphone were set on the table.

\section{Examiner Reliability}

Interjudge reliability of this examiner for timing DIO rates was determined to be acceptable for the syllable production tasks when this examiner and two Portland State University speech-language pathology graduate students agreed within .2 seconds (at half speed) in timing 90 percent of ten sample DIO tasks from an audio tape. Each of the seven syllable combinations reached reliability. Reliability of the two oral movement tasks was achieved at the 90 percent level within .4 seconds on ten face-to-face samples. Videotaping the lip bounces and teeth clicks was attempted, but the poor quality of the video equipment prevented clear filming.

Intrajudge reliability for timing DIO rates was achieved by this examiner for each syllable task seven days following establishment of interjudge reliability. The sample audio tape used for interjudge reliability was re-timed and the examiner timed 90 percent of the ten samples within .2 seconds of her original measurements.

\section{Sounds and Movements Tested}

The sounds produced by the subjects, in the order of the testing, were twenty productions of single syllables $/ \mathrm{p} \wedge /, / \mathrm{l} \wedge /$, and $/ \mathrm{k} \wedge /$, fifteen

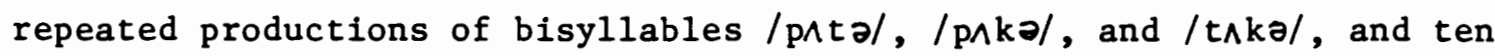
repeated productions of the trisyllable /p^təkə/. Oral movements used were twenty "teeth clicks" (a rapid opening and closing of the jaw) and 
twenty "lip bounces" (a rapid opening and closing of the 1ips). Each task was performed three times for a total of twenty-seven events.

\section{Method of Measuring Data}

The time-by-count method was employed in this study. DIO rates were determined by the length of time it took to repeat twenty single syllables, fifteen double syllables, ten trisyllables, twenty teeth clicks, and twenty lip bounces.

All recordings were made at a tape speed of $71 / 2$ inches per second (IPS). The tape was played back and timed at $33 / 4$ IPS.

\section{Procedure}

\section{Subject Selection}

Each potential subject was screened by answering an oral questionnaire (see Appendix $B$ ) and producing $/ \mathrm{p} \wedge /, / \mathrm{t} \wedge /$, and $/ \mathrm{k} \wedge /$ in isolation. The subject also participated in a short conversation with the examiner about the nature of the study. The examiner listened to and observed the potential subject during the screening, making a subjective judgement on the neurological status and articulation ability of the potential subject. If it was discovered, during the conversation or questionnaire completion, that the subject had a reported or observed interference with speech, he or she was dismissed as a subject. Potential subjects also were dismissed if they reported dentures interfering with the speed of their speech, drinking an alcoholic beverage in the previous eight hours, a seizure in the previous forty-eight hours, ingesting a minor tranquilizer in the previous two days or taking any major tranquilizers or antipsychotics. 
All drugs regularly taken and those taken in the previous forty-eight hours were noted on the questionnaire for future reference. The wearing of dentures also was noted, even if they were non-interfering. The examiner carried and referred to the Physician's Desk Reference (1980) when needed. No subject had been pre-informed of the task, nor had they practiced beforehand.

\section{$\underline{\text { Testing Procedure }}$}

Each subject was instructed as follows:

"You're going to be saying seven series of nonsense syllables involving the sounds $/ \mathrm{p} \wedge /, / \mathrm{t} \wedge /$, and $/ \mathrm{k} \wedge /$. You are also going to do two series of mouth movements. You will be saying or doing each series three times. When you do this, repeat the syllables as fast as you can. I'11 be counting and let you know when to stop. You will be saying each syllable more than twenty times, so you need to keep on going. I'll give you a break between each set of syllables."

For practice, the examiner demonstrated the procedure of repeating a syllable or movement as quickly as possible. The subject performed the task and was told to ". . . do it again, even faster this time." The examiner repeated this step for each of the nine tasks.

When the subject demonstrated understanding of the task, the examiner said, "Ready?" and waited for acknowledgement from the subject. For the syllables, a tape recorder was turned on, the examiner said "/p^/ one" (or the appropriate task and number) and the subject performed the task. The tape recorder was turned off for a moment while the subject took a deep breath, and the procedure was repeated twice. After the seven syllable tasks were tape recorded, the subject performed the oral 
movement tasks. These oral movements were counted and timed by the examiner during performance.

\section{Data Measurement and Analysis}

Each DIO task was recorded at 7 1/2 IPS, played back at $33 / 4$ IPS, and timed to a hundredth of a second using the stop watch. The mean of each subject's three productions for each task was determined and divided by two for the purpose of converting back to $71 / 2$ IPS. This procedure resulted in the mean amount of time for performance of the repeated syllables. Thus, the time for a predetermined number of syllable productions was obtained for each task performed by every subject. The mean time and standard deviation was then determined for each decade and each task and displayed in tabular form. Additionally, mean times and standard deviations were determined for men and women within each decade. 
CHAPTER IV

RESULTS AND DISCUSSION

\section{Results}

The purpose of this study was to develop preliminary normative data on the speed of oral diadochokinesis (DIO) used in articulation of syllables and oral motor movements by adults. The essential question was: What are the mean rates of oral diadochokinetic syllable productions and of selected oral movements for each decade of adulthood? The answer to the question may be found in Table I.

The data were analyzed by determining a mean and standard deviation for each task within a decade. The means and standard deviations for each task for each decade from twenty to twenty-nine through eighty and over appear in chart form in Table I. Raw data for each subject appears in Appendix C. The DIO rates collected were slightly slower for older subjects than for younger subjects, indicating there is a tendency of decreased DIO speed with increased age. Exceptions to this trend are the twenties, forties, and fifties. The forties were fastest on most productions while the twenties were often slower than the thirties. Additionally, the fifties were fastest on one task. It also is noted that the standard deviations increase with each successive decade's performance.

The means for $/ \mathrm{p} \wedge /$ ranged from 2.67 (S.D.=.30, 30's; S.D.=.32, 40's) to 3.17 (S.D.=.52, $\left.80^{\prime} \mathrm{s}\right)$. The means for $/ \mathrm{tA} /$ ranged from 2.70 (S.D.=.37, $\left.40^{\prime} \mathrm{s}\right)$ to $3.27\left(\mathrm{~S} . \mathrm{D} .=.45,80^{\prime} \mathrm{s}\right)$. The means for $/ \mathrm{k} \wedge /$ ranged from 2.86 


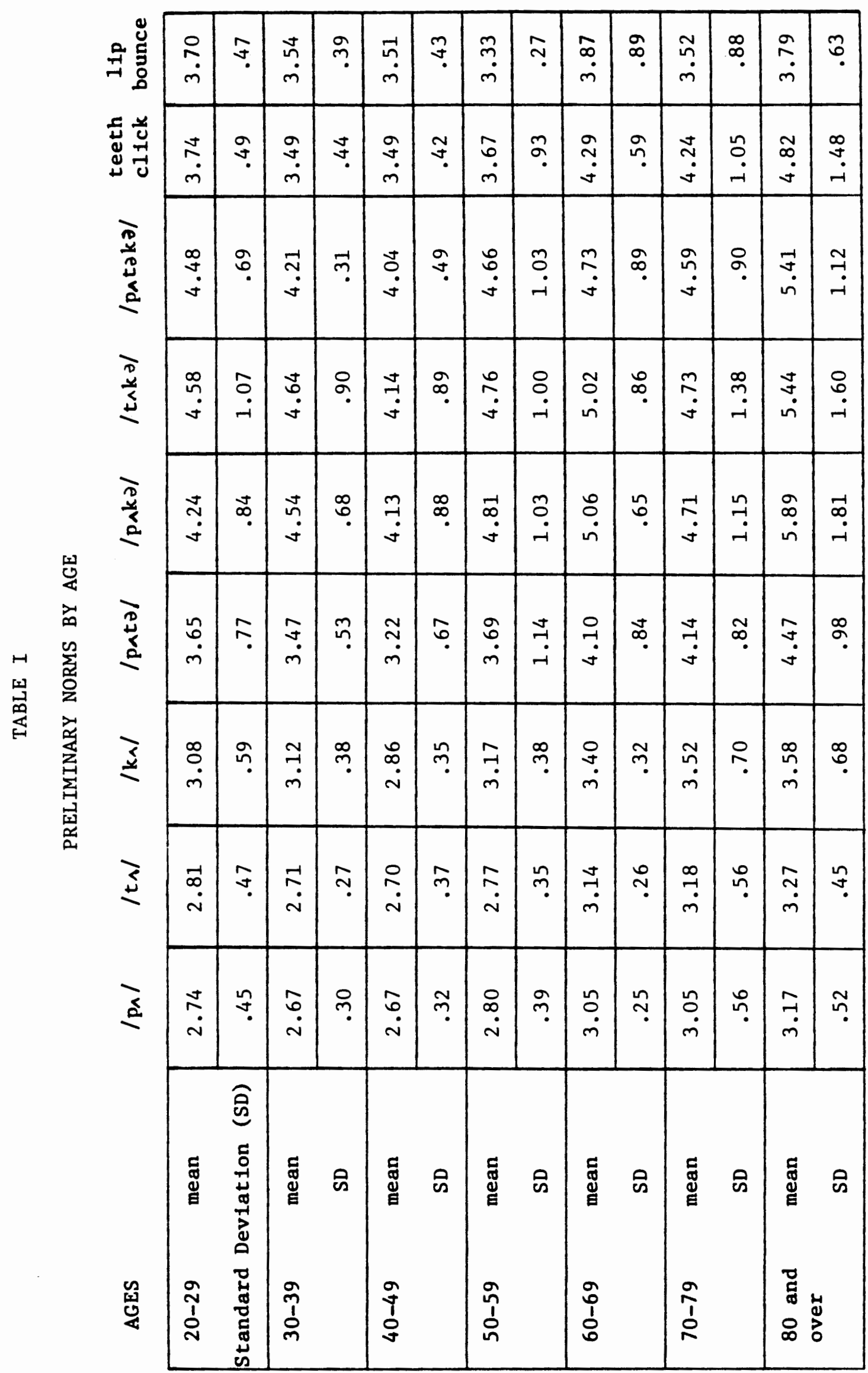


$\left(S . D .=.35,40^{\prime} s\right)$ to $3.58\left(S . D .=.68,80^{\prime} \mathrm{s}\right)$. The means for $/ \mathrm{p} \wedge t \partial /$ ranged from 3.22 (S.D.=.67, $40^{\prime} \mathrm{s}$ ) to $4.47\left(\mathrm{~S} . \mathrm{D} .=.98,80^{\prime} \mathrm{s}\right)$. The means for $/ \mathrm{p} \wedge \mathrm{ka} /$ ranged from 4.13 (S.D. $=.88,40^{\prime} \mathrm{s}$ ) to 5.89 (S.D. $=1.81,80^{\prime} \mathrm{s}$ ). The means for $/ \mathrm{t} \wedge \mathrm{k} \partial /$ ranged from $4.14\left(\mathrm{~S} . \mathrm{D} .=.89,40^{\prime} \mathrm{s}\right)$ to $5.44\left(\mathrm{~S} . \mathrm{D} .=1.60,80^{\prime} \mathrm{s}\right)$. The means for /p^takə/ ranged from 4.04 (S.D.=.49, 40's) to 5.41 (S.D.= $\left.1.12,80^{\prime} \mathrm{s}\right)$. The means for teeth click ranged from 3.49 (S.D. $=.42,40^{\prime} \mathrm{s}$; S.D. $\left.=.44,30^{\prime} \mathrm{s}\right)$ to $4.82\left(S . D .=1.48,80^{\prime} \mathrm{s}\right)$. The means for 1ip bounce ranged from $3.33\left(S . D .=.27,50^{\prime} s\right)$ to $3.79\left(S . D .=.63,80^{\prime} s\right)$.

Separate means and standard deviations also were computed for male and female DIO rates within each decade. The summary of the male and female data appears in Tables II and III, respectively.

The means for $/ \mathrm{p} \wedge /$ ranged from 2.53 (S.D. $=.23,50^{\prime} \mathrm{s}$ men) and 2.70 $\left(S . D .=.34,20^{\prime} \mathrm{s}\right.$ women) to $3.30\left(S . D .=.60,80^{\prime} \mathrm{s}\right.$ men $)$ and $3.28(S . D .=.71$, $70^{\prime}$ 's women). The means for $/ t \Lambda /$ ranged from 2.59 (S.D.=.27, 40's men) and 2.71 (S.D. $=.25,30^{\prime} \mathrm{s}$ women) to $3.43\left(\mathrm{~S} . \mathrm{D} .=.46,80^{\prime} \mathrm{s}\right.$ men) and 3.44 (S.D.=.67, $70^{\prime} \mathrm{s}$ women). The means for $/ \mathrm{k} \wedge /$ ranged from 2.74 (S.D.=.32, $40^{\prime} \mathrm{s}$ men) and 2.98 (S.D.=.37, $40^{\prime} \mathrm{s}$ women) to $3.87\left(\mathrm{~S} . \mathrm{D} .=.71,80^{\prime} \mathrm{s}\right.$ men $)$ and 3.85 (S.D.=.81, 70's women). The means for /p^ta/ ranged from 3.05 $\left(S . D .=.52,40^{\prime} \mathrm{s}\right.$ men $)$ and $3.39\left(S . D .=.80,40^{\prime} \mathrm{s}\right.$ women $)$ to $4.23(\mathrm{~S} . \mathrm{D} .=.66$, $80^{\prime} \mathrm{s}$ men) and 4.71 (S.D.=1.23, $80^{\prime} \mathrm{s}$ women). The means for $/ \mathrm{p} \wedge \mathrm{k}$ / ranged from 3.93 (S.D.=.81, 70's men) and $4.26\left(S . D .=1.28,40^{\prime} \mathrm{s}\right.$ women) to 5.78 $\left(S . D .=1.68,80^{\prime} \mathrm{s}\right.$ men $)$ and $6.01\left(S . D .=2.09,80^{\prime} \mathrm{s}\right.$ women). The means for $/ \mathrm{t} \wedge \mathrm{k} / \mathrm{l}$ ranged from 3.83 (S.D.=.33, 40's men) and 4.46 (S.D.=1.19, 40's women) to 5.48 (S.D. $=1.68,80^{\prime} \mathrm{s}$ men) and 5.59 (S.D.=1.04,70's women).

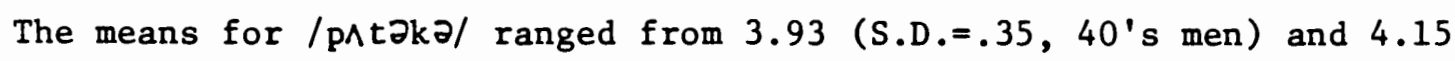
$\left(S . D .=.61,40^{\prime} \mathrm{s}\right.$ women) to $5.10\left(\mathrm{~S} . \mathrm{D} .=1.11,80^{\prime} \mathrm{s} \operatorname{men}\right)$ and $5.72(\mathrm{~S} . \mathrm{D} .=1.14$, 80 's women). The means for teeth click ranged from 3.26 (S.D.=.18, 40's 


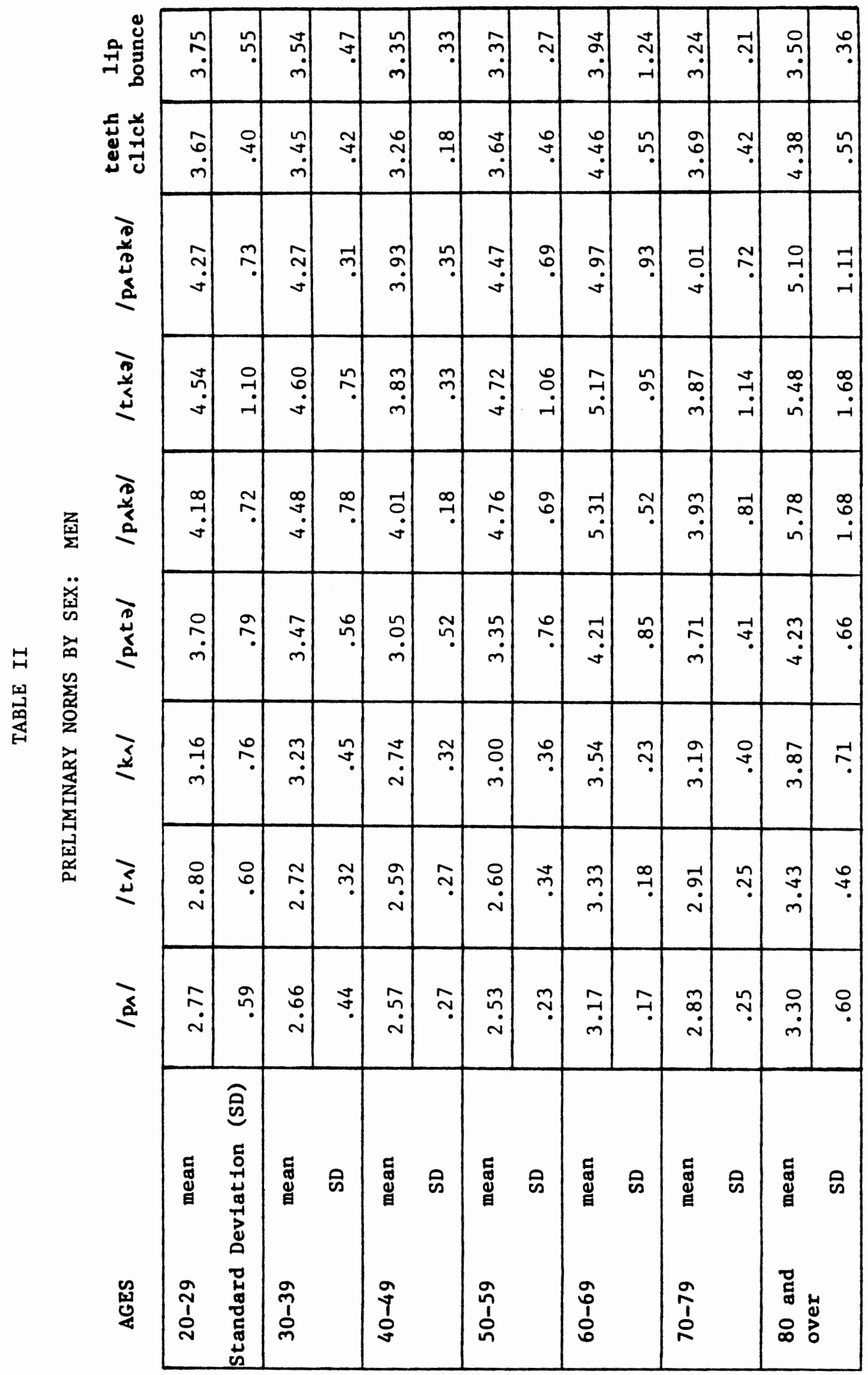




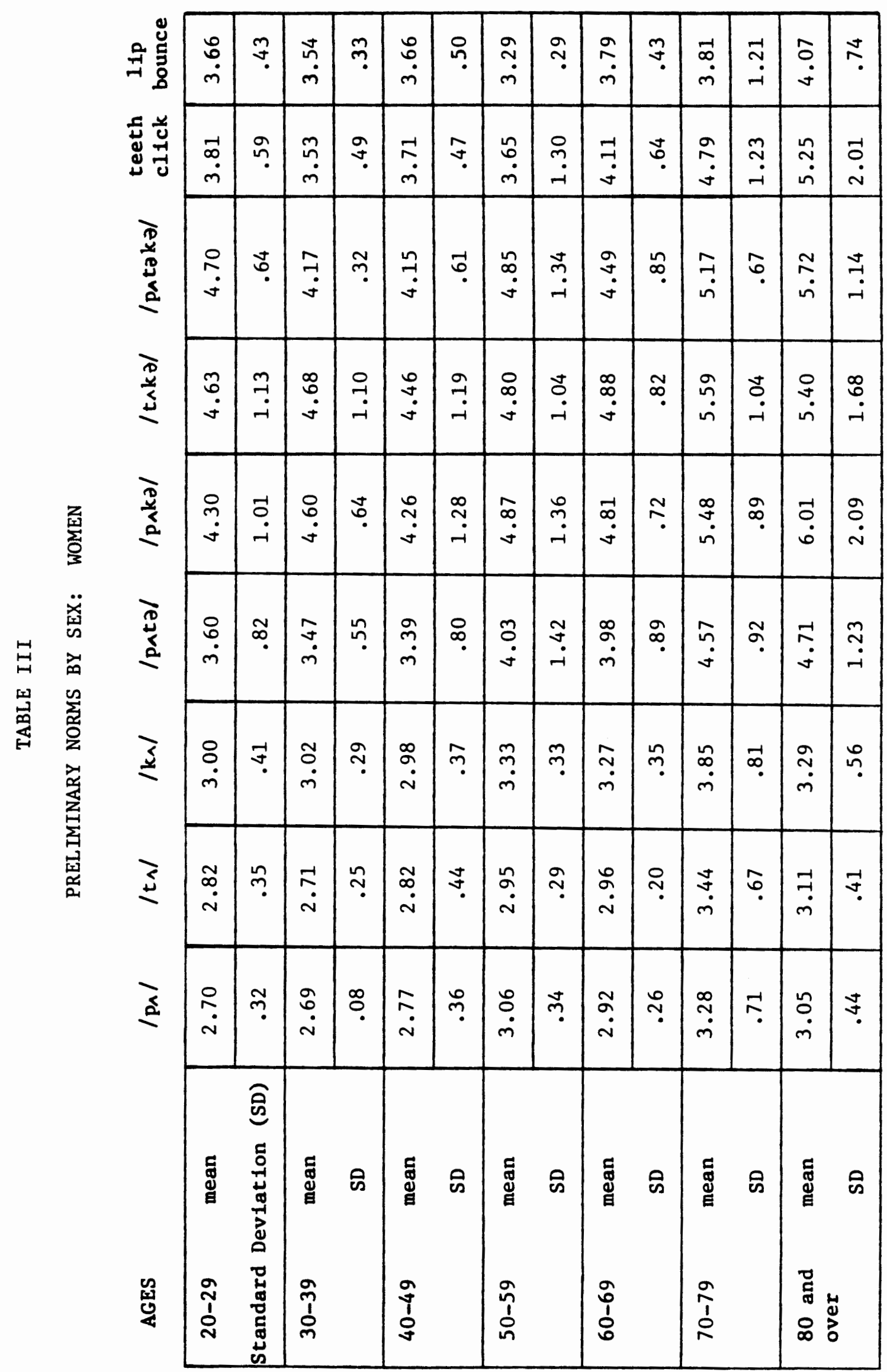


men) and 3.53 (S.D. $=.49,30^{\prime} \mathrm{s}$ women) to $4.46\left(\right.$ S.D. $=.55,60^{\prime} \mathrm{s}$ men $)$ and 5.25 (S.D. $=2.01,80^{\prime}$ s women). The means for lip bounce ranged from 3.24 $\left(S . D .=.21,70^{\prime} \mathrm{s}\right.$ men $)$ and $3.29\left(S . D .=.29,50^{\prime} \mathrm{s}\right.$ women) to 3.94 (S.D.=1.24, $60^{\prime}$ 's men) and 4.07 (S.D. $=.74,80^{\prime}$ 's women).

\section{$\underline{\text { Discussion }}$}

The purpose of this investigation was to develop preliminary normative data on the speed of oral diadochokinesis (DIO) used in articulation of syllables and oral motor movements by adults. The resulting preliminary norms of DIO rates were generally slower for older subjects than for younger subjects, indicating there is a tendency of decreased DIO speed with increased age, except for the decades twenty and forty. The forties were fastest, while the twenties were slower than the thirties. It must be noted that although DIO speed decreased with age, the rates of production were very similar. The fastest decade fell within one standard de-

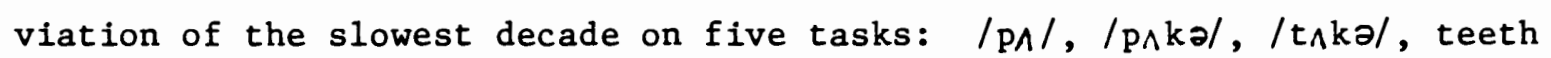
click and lip bounce. The fastest decade fell within two standard deviations of the slowest decade on the other four tasks: $/ \mathrm{t} \Lambda /, / \mathrm{k} \wedge /, / \mathrm{p} \wedge t z /$, and $/ \mathrm{p} \wedge t \partial \mathrm{k} \partial /$. Because the trend of decreased speed is so slight, and the fastest and slowest decades' speeds fall within two standard deviations of each other, the differences are not clinically significant. Additionally, because of the small number of subjects in each decade, one or two comparatively fast or slow subjects may have easily skewed the data. These findings agree with Kreul's (1972) contention that there is little difference in the speed of single syllables repeated by younger and older adults. 
In agreement with Ptacek et al. (1966) is the occurrence of an increase in standard deviation size with an increase in age. In this study, there was a tendency for the standard deviations of each syllable or movement to increase with age. The standard deviation more than tripled on the /p^taka/ from .31 seconds for the 30-year-olds to 1.12 seconds for the 80-plus-year-olds. Possible factors of aging involved in the resulting "wider range of normal" indicated by the standard deviation increase may be: fatigue, lack of motivation, unseen or unreported neurological deficits or drugs not included or excluded from the screening. One subject, aged 94, passed the screening and participated in the study. Her score was eliminated, however, because it was more than twice the time of others in her decade. Another subject, aged 87, passed the screening but quit in the middle of the test due to fatigue; his score was also eliminated.

of the single syllable tasks, $/ \mathrm{p} \wedge /$ was generally fastest across the ages, while $/ \mathrm{kN} /$ was slowest. This finding is in agreement with Blomquist (1950) and Lundeen (1950), who speculated the speed of DIO is often dependent on the developmental order and the location in the mouth of the sound produced. Sounds developed earliest and produced nearest to the front of the mouth were the fastest repeated syllables (Lundeen, 1950). Comparing results of individual subjects' three trials of each task supports Blomquist's (1950) contention that there does not appear to be a "practice" effect in performing DIO tasks. Instead there appears to be a "fatigue" effect. Often the subject's slowest performance was on the third trial of a particular syllable, while the fastest performance occurred on the first or second trial.

Although calibrated in the task of counting and timing 1 ip bounces 
and teeth clicks, this examiner believes the accuracy of counting and timing may have influenced the results. Because these rates were taken from a live performance, rechecking was impossible. Weiss et al. (1980), however, note that if the repetitions are too rapid to count live, rate is probably not impaired in that client.

Results from the incidental preliminary normative data on male and female DIO rates indicate disagreement with both Ptacek et a1. (1966) and Kreul (1972). Ptacek et al. found young adult women to be faster at multisyllable tasks than young adult men, and the young adult men to be faster at single syllables than young adult women. Ptacek et al. also found older men to be faster than older women at all tasks. Kreul found younger men to be faster than younger women and older women faster than older men. This study found men and women to be approximately equal in speed of performance in the twenties, thirties and eighties. Men were faster than women in their forties, fifties and seventies, and women in their sixties were faster than the men.

In summary, this investigation resulted in the formation of preliminary normative data on DIO rates of adults of all ages. The results indicate a slight trend of decreasing speed with increasing age, as well as an increase in standard deviation of DIO rates with increasing age. The sounds produced in the front of the mouth were faster than those produced in the back of the mouth, and males and females were determined to be approximately equal in DIO speed throughout adulthood. 


\section{CHAPTER V}

\section{SUMMARY AND IMPLICATIONS}

\section{Summary}

In the clinical evaluation and management of speech disorders, a speech-language pathologist may observe disturbances in a client's motor abilities that suggest possible neurological dysfunction. One possible disturbance is in oral diadochokinesis (DIO), an individual's ability to start and stop the movement of the articulators rapidly and execute repetitive, alternating, sequential movements typically associated with speech articulation. It is often recommended that a speech-1anguage pathologist test DIO speed and compare the performance to available norms. There is, however, a lack of normative DIO data spanning all ages of adulthood. The purpose of this study was to develop preliminary normative data on the speed of oral diadochokinesis used in articulation of syllables and oral movements by adults. The investigation sought to answer the question: What are the mean rates of oral diadochokinetic syllable productions and selected oral movements for each decade of adulthood?

Eighty-four subjects participated in this study, six men and six women from each decade of adulthood, beginning with the decade twenty to twenty-nine and ending with eighty and older. Subjects displayed no observable neurologies or articulation errors, and they reported no history of neurological impairment, 1ll-fitting dentures, respiratory disorders, 
or recent ingestion of speed-affecting drugs.

Subjects were instructed to repeat at least twenty productions of $|\mathrm{p} \wedge /,| \mathrm{t} \wedge /$, and $/ \mathrm{k} \wedge /$, fifteen productions of $/ \mathrm{p} \wedge t \partial /, / \mathrm{p} \wedge \mathrm{k} \partial /$, and $/ \mathrm{t} \wedge \mathrm{k} \partial /$, ten productions of /p^takə/ and twenty teeth clicks and lip bounces as quickly as possible. They repeated each series of syllables or movements three times. The movements were counted and timed on the spot, while the syllables were tape recorded. The tape was played back at half speed, the productions were counted, timed and calculated into means and standard deviations for each decade.

Results of this study revealed a slight tendency toward decreased DIO speed as age increases, although the speed of the fastest decade for five tasks was within one standard deviation of the speed of the slowest decade and within two standard deviations for the other four tasks. Sounds produced at the front of the mouth also were observed to be faster than those produced at the back of the mouth.

Data were collected on the speed of males and females. Men and women performed at approximately equal speeds in the twenties, thirties, and eighties. Men in their forties, fifties, and seventies were faster than the matched women, while women in their sixties were faster than the men.

\section{Implications}

\section{Clinical}

This study produced a table of preliminary normative data on adult oral diadochokinetic rates. It is reasonable to infer that clinical use of the same syllables, with rates obtained using the same methods on normal, healthy adults, would result in similar findings. Exceptions and 
cautions to this statement are listed below.

Results from this study revealed a slight trend toward decreased DIO speed with increased age, except for the decades twenty and forty. The forties were the fastest, while the twenties were slower than the thirties. Because of the small number of subjects in each decade, one or two comparatively fast or slow subjects may have easily skewed the data. In clinical situations it is cautioned, therefore, to use the data as indicative of a general trend of performance rather than using the preliminary norms in a firm fashion.

\section{$\underline{\text { Research }}$}

It appears DIO rates decrease with increased age based on this study. The decrease in speed, however, is slight and may not be clinically significant. Further research, using a larger number of subjects, is indicated for confirmation of this finding.

Another study indicated is continuation of this study. Additional subjects in each decade would be tested, and their rates pooled with the rates from this study.

The findings of past studies indicate no norms based on the timeby-count method, using both single and multiple syllable tasks, are available for children under the age of six or between the ages of fourteen and nineteen. Because the time-by-count method is the currently recommended method of obtaining DIO rates in many speech-language pathology textbooks, research on norms for these age groups is indicated.

In obtaining data for this study, there appeared to be a "fatigue effect" by repeating the same task three times in sequence. It may be enlightening to compare rates of a study done with only one trial per 
syllable task, rather than three trials. Another variation would be to gather data one trial per syllable task, then repeat the entire sequence two more times.

Some subjects in this study were "slow talkers," while others spoke rapidly in conversation. Some occupations, such as disk jockeys or auctioneers, require quite rapid speech. It might be useful to know if rapid or slow speech affects DIO ability.

Verification of lip bounce and teeth click rates may be obtained using state-of-the-art video-audio equipment. This technique also may be used to collect data using an increased number of subjects. 


\section{SELECTED BIBLIOGRAPHY}

ALBRIGHT, R.W., The motor abilities of speakers with good and poor articulation. Speech Monographs, 1948, 15, 164-172.

BIRREN, J.E., The significance of age change in speed of perception and psychomotor skills. In Anderson, J.E. (Ed.), Psychological Aspects of Aging. Washington: American Psychological Association (1956).

BLOMQUIST, B.L., Diadochokinetic movements of nine-, ten-, and elevenyear-old children. JSHD, 1950, 15, 159-164.

CANNING, B.A. and ROSE, M.F., Clinical measurements of the speed of tongue and lip movements in British children with normal speech. British Journal of Disorders of Communication, $1974,9,45-50$.

CANTER, G.J., Speech characteristics of patients with Parkinson's disease: III. articulation, diadochokinesis, and overall speech adequacy. JSHD, $1965,30,217-224$.

CLARK, A. (D.D.S.), personal interview (1981).

DARLEY, F.L., ARONSON, A.E., and BROWN, J.R., Motor Speech Disorders. Philadelphia: W.B. Saunders Co. (1975).

DE JONG, R.N., The Neurologic Examination. (3rd ed.) New York: Harper and Row (1967).

DWORKIN, J.P., Protrusive lingual force and diadochokinetic rates: a comparative analysis between normal and lisping speakers. LSHSS, $1978,9,8-16$.

EMERICK, L.L. and HATTEN, J.T., Diagnosis and Education in Speech Pathology. Englewood Cliffs: Pentice-Ha11, Inc. (1974).

ENGLISH, R.H., personal interview (1982).

FAIRBANKS, G. and SPRIESTERSBACH, D.C., A study of minor organic deviations in 'functional' disorders of articulation: 1 . rate of movement or oral structures. JSHD, 1950, 15, 60-69.

FLETCHER, S.G., The Fletcher Time-by-Count Test of Diadochokinetic Sy1lable Rate. Tigard, Oregon: C.C. Publications, Inc. (1978).

FLETCHER, S.G., Time-by-count measurement of diadochokinetic syllable rate. JSHR, $1972,15,763-770$. 
HUTCHINSON, G.G., HANSON, M.L., and MECHAM, M.J., Diagnostic Handbook of Speech Pathology. Baltimore: Williams and Wilkins Co. (1979).

IRWIN, J.V. and BECKLUND, 0., Norms for maximum repetitive rates for certain sounds established with the sylrater. JSHD, 1953, 18, 149-160.

JENKINS, R.L., The rate of diadochokinetic movement of the jaw at the ages from seven to maturity. JSD, 1941, 16, 13-22.

JOHNSON, J.P., Nature and Treatment of Articulation Disorders. Springfield: Charles C. Thomas (1980).

KREUL, E.J., Neuromuscular control examination for Parkinsonism: vowel prolongations and diadochokinetic and reading rates. JSHR, 1972, $15,77-83$.

LUNDEEN, D.J., The relationship of diadochokinesis to various speech sounds. JSHD, 1950, 15, 54-59.

MAYO CLINIC, Clinical Examinations in Neurology. Philadelphia: W.B. Saunders (1964).

PETTIT, C.W., Diadochokinesis of the Musculature of the Jaw During Puberty and Adolescence. Unpublished Master's Thesis: University of Wisconsin (1939).

Physician's Desk Reference. (34th ed.) Oradell, N.J.: Medical Economics Company (1980).

PRINS, T.D., Motor and auditory abilities in different groups of children with articulatory deviations. JSHR, 1962, 15, 161-168.

PTACEK, P.H., SANDER, E.K., MAIONEY, W.H., and JACKSON, C.C., Phonatory and related changes with advancing age. JSHR, 1966, 9, 353-360.

ROUSEY, C.L. and MORIARTY, A.E., Diagnostic Implications of Speech Sounds. Springfield: Charles C. Thomas (1965).

SCHLANGER, B.B., The Rate of Diadochokinetic Jaw Movement of Young Children in the Age Groups Seven, Eight and Nine. Unpublished Master's Thesis: University of Wisconsin (1939).

SCHMERTZLER, L. (M.D.), personal interview (1981).

SIGURD, B., Maximum rate and minimal duration of repeated syllables. Language and Speech, 1973, 16, 373-395.

STROTHER, C.R. and KRIEGMAN, L.S., Diadochokinesis in stutterers and nonstutterers. JSD, $1943,8,323-335$.

WEISS, C.E., The relationships between maximum articulatory rate and articulatory disorders among children. Central States Speech Journal, $1968,19,185-187$. 
WEISS, C.E., LILLYWHITE, H.S., and GORDON, M.E., Clinical Management of Articulation Disorders. St. Louis: C.V. Mosby Co. (1980).

WERTZ, R.T., Neuropathologies of speech and language: an introduction to patient management. In Johns, D.F. (Ed.), Clinical Management of Neurologic Communicative Disorders. Boston: Little, Brown and Co. (1978).

WEST, R., ANSBERRY, M., and CARR, A., The Rehabilitation of Speech. (3rd ed.) New York: Harper and Brothers (1957). 
APPENDIX A

\section{SPECIFICATIONS}

\section{Recorder: SONY-MATIC}

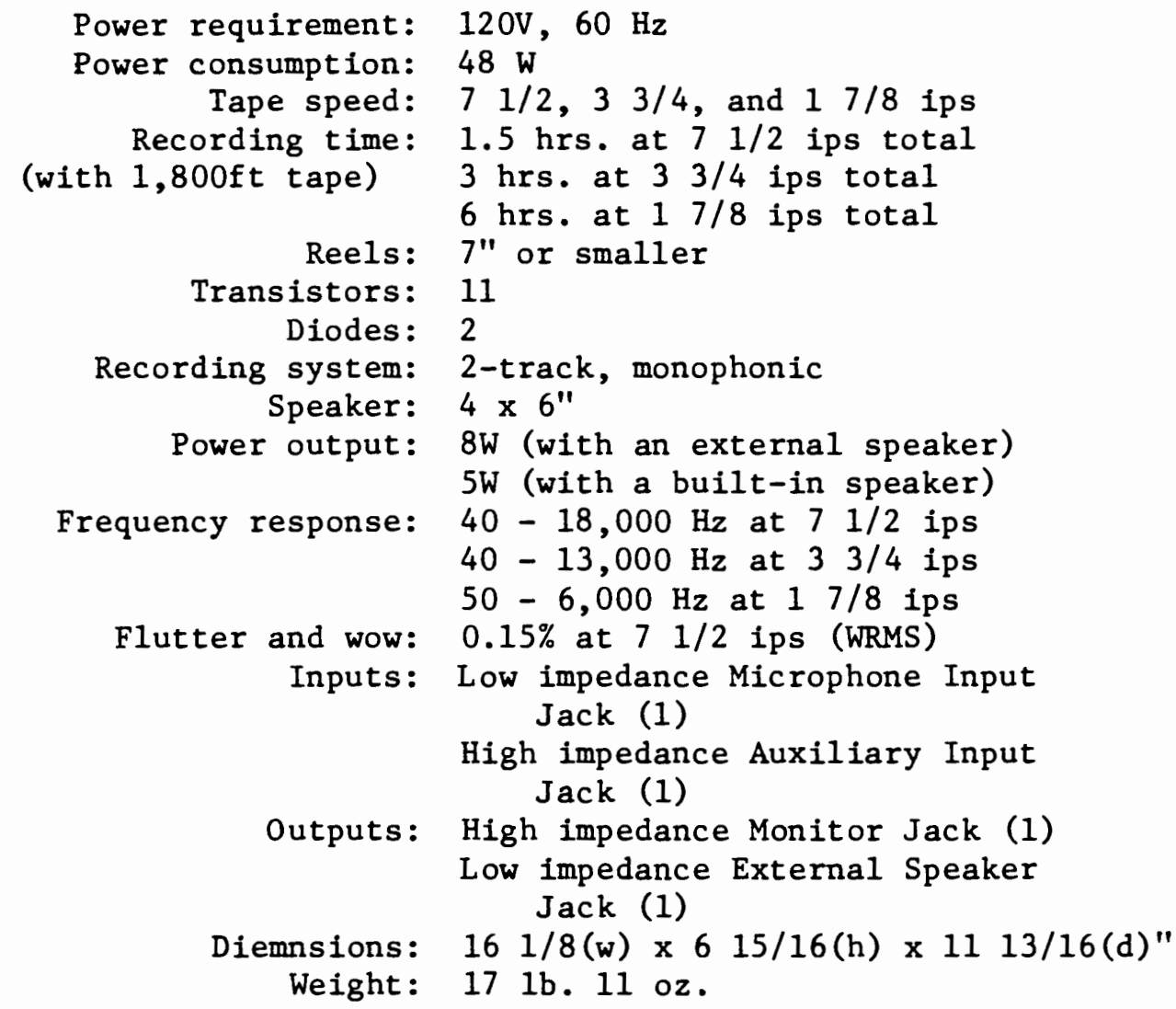

\section{Realistic Reel-to-Reel Audio Recording Tape}

The Realistic "High Fidelity" reel-to-reel audio recording tape is 0.5 mil thick on a tensilized polyester base. It is catalogue number 44-766A. 


\section{APPENDIX B}

\section{SUBJECT QUESTIONNAIRE}

DATE:

NAME:

AGE :
Subject No.

Tape

Number

MALE/FEMALE

BIRTHDATE :

1. Have you ever had an illness or accident that affected your speech, such as:
a. a stroke?
f. muscular dystrophy?
b. Parkinson's disease?
g. emphysema?
c. myasthenia gravis?
h. severe asthma attacks?
d. cerebral palsy?
i. history of uncontrolled seizures?
e. multiple sclerosis?
j. other?

2. Have you

a. had a seizure within the past 48 hours?

b. had an alcoholic beverage within the past 8 hours?

3. Do you wear dentures?

Upper, lower, or both?

Do you believe they interfere with the speed of your speech?

4. What drugs do you regularly take?

What drugs have you taken within the past 48 hours?

5. Say: $/ \mathrm{p} \wedge /, / \mathrm{t} \wedge /, / \mathrm{k} \wedge /$. 


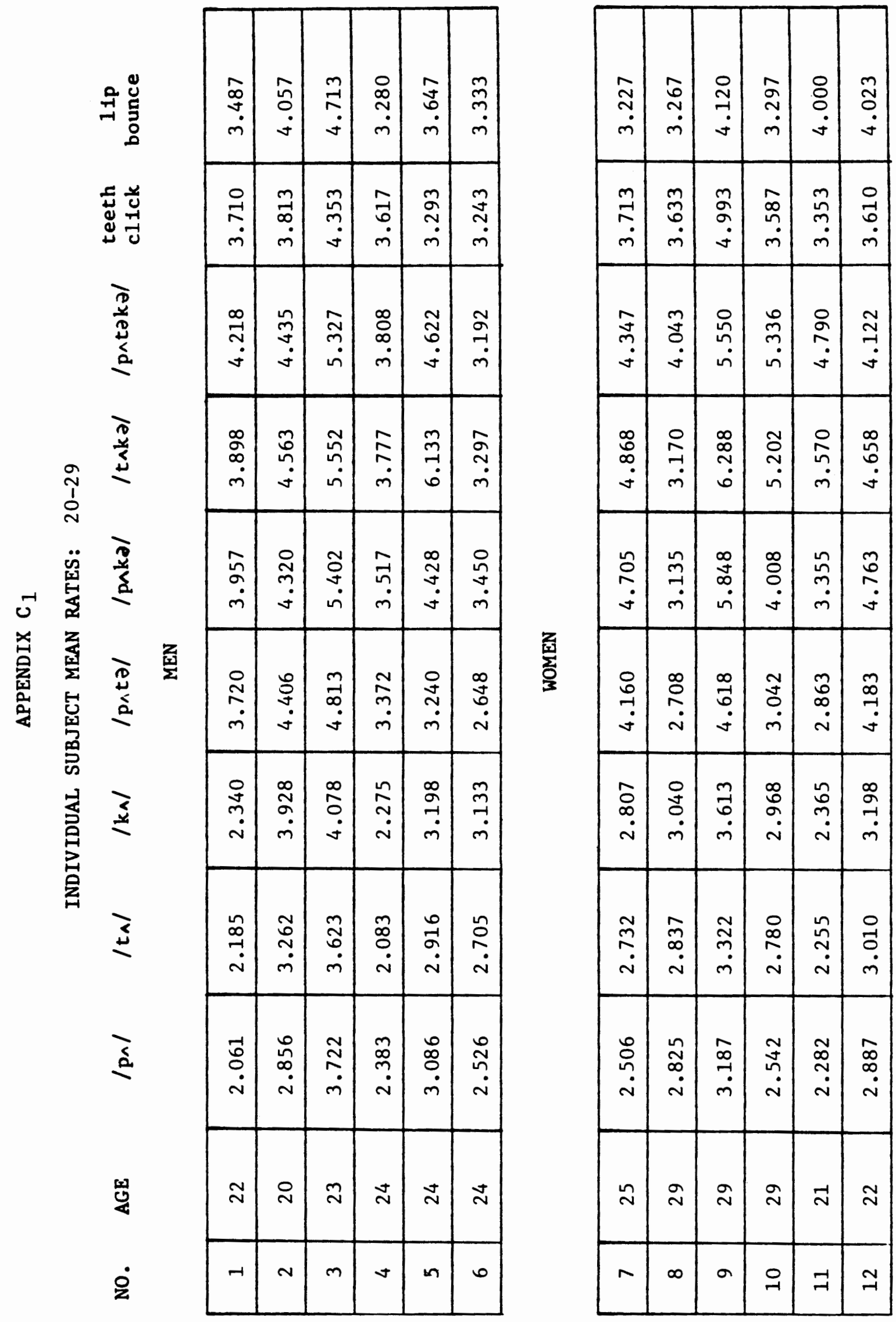




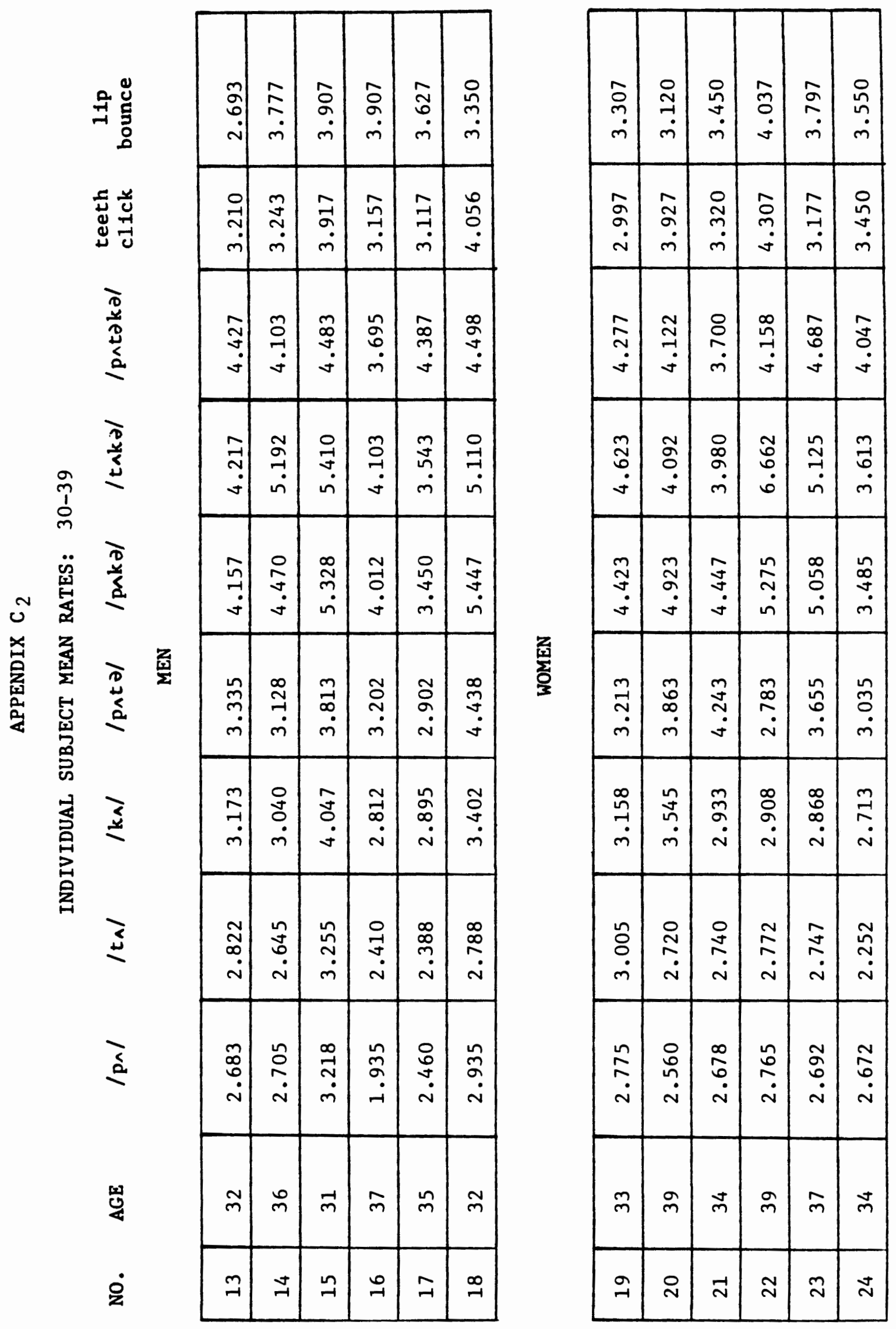




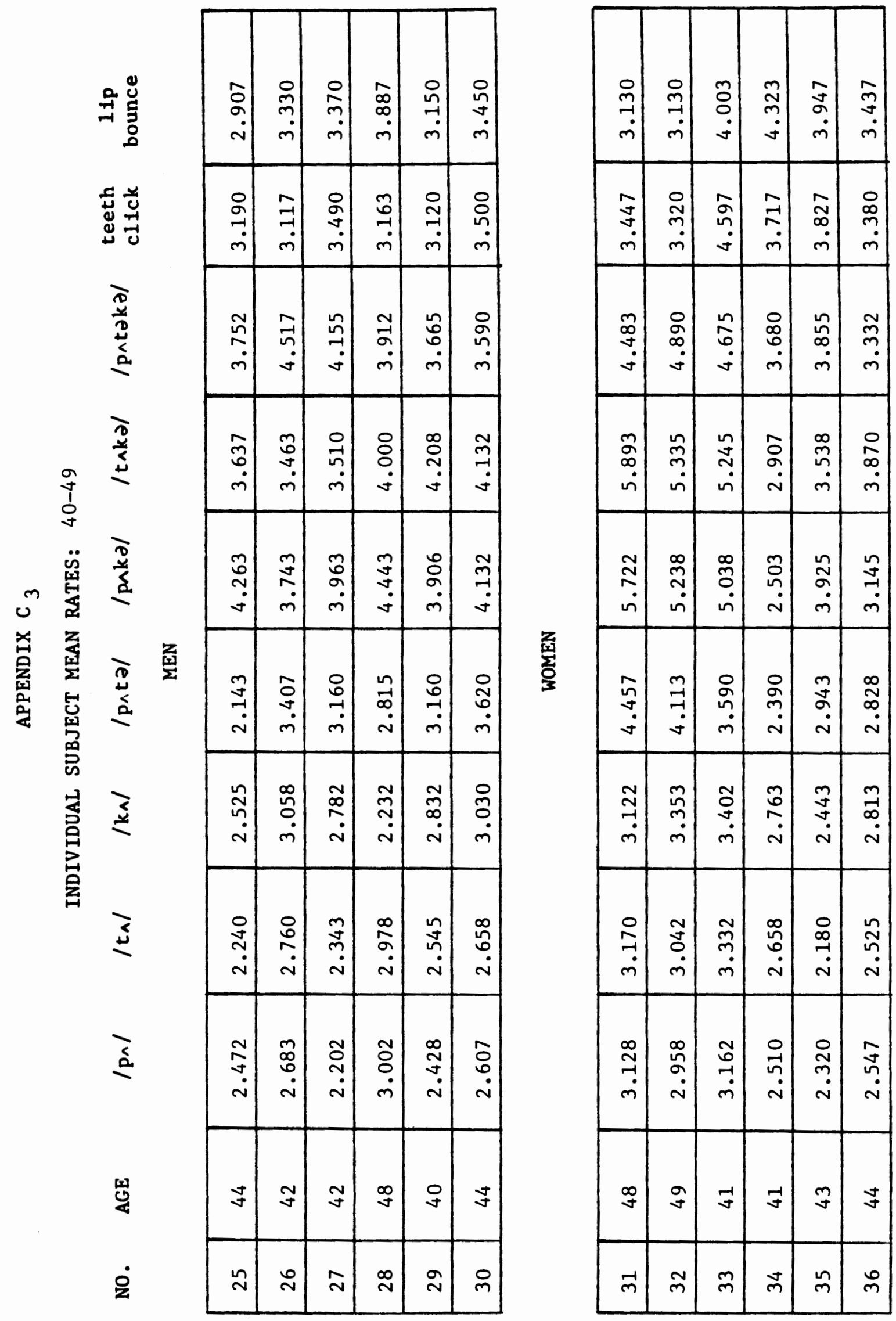




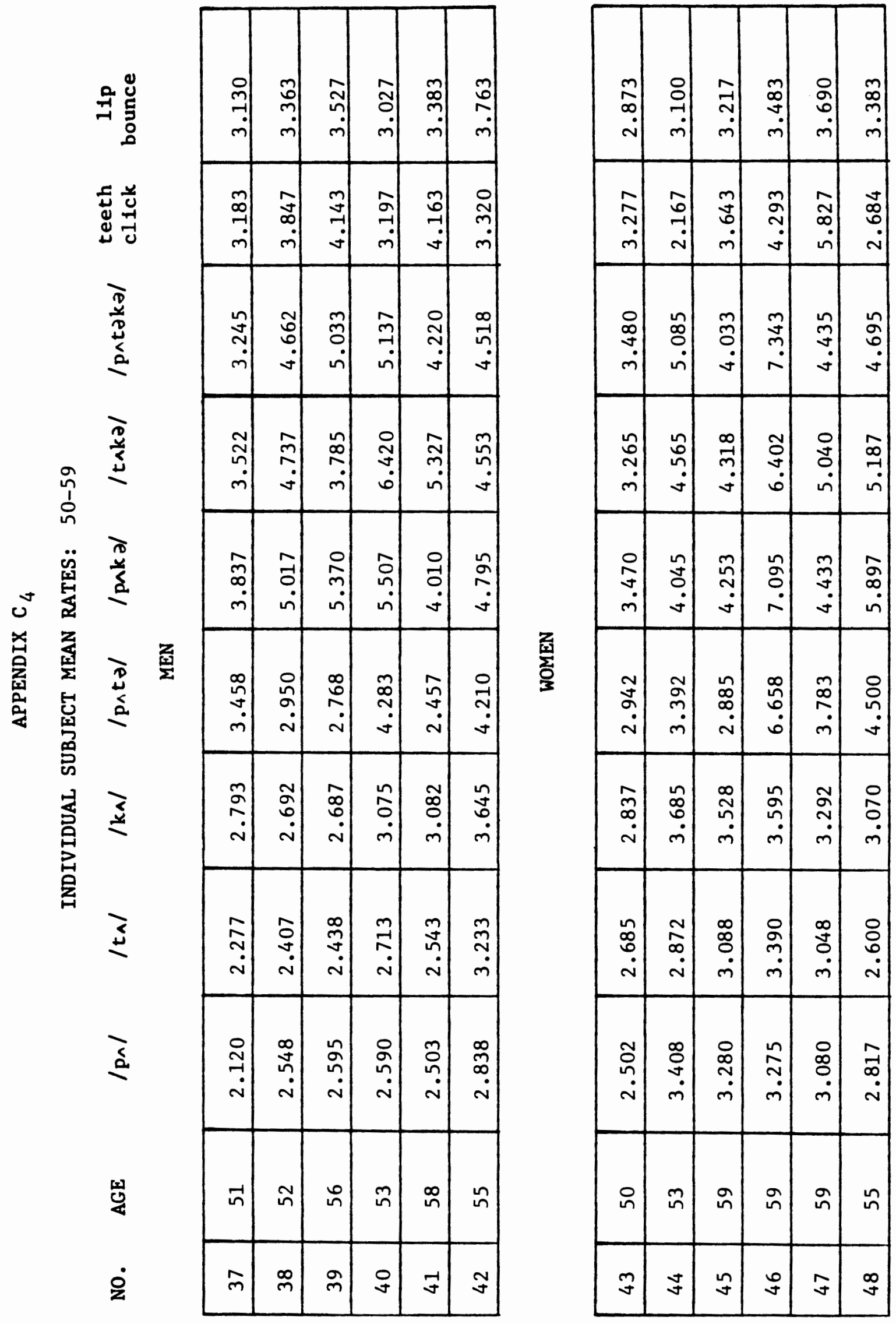




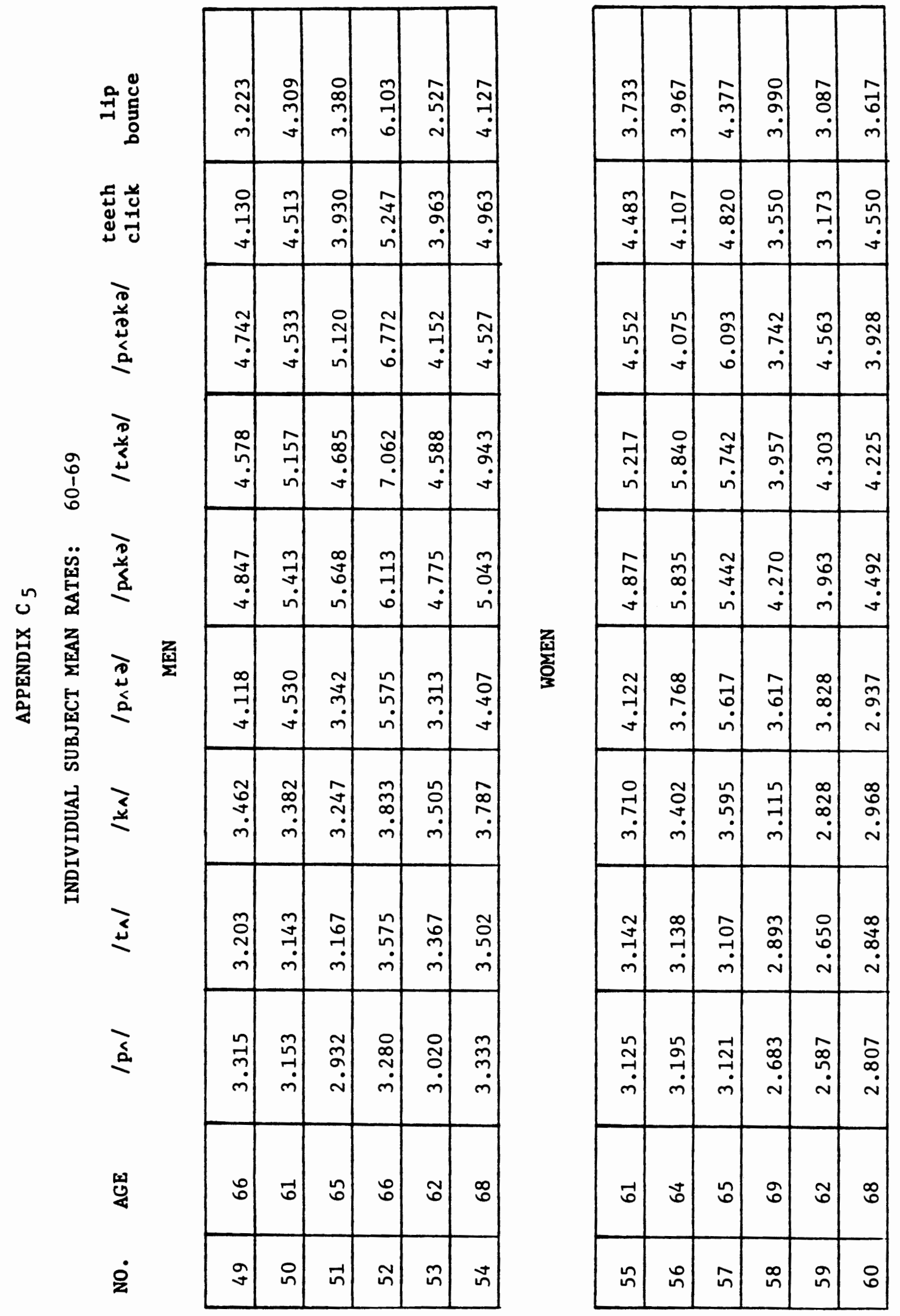




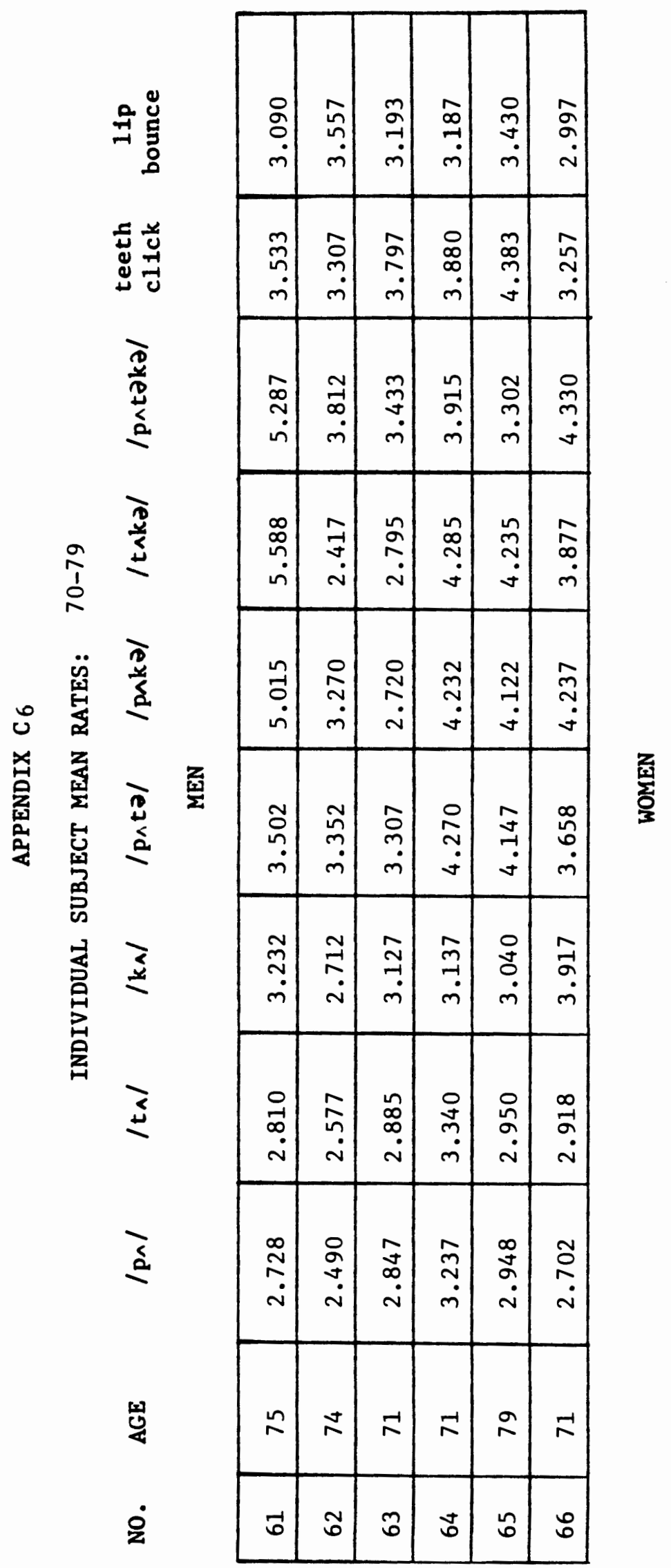

\begin{tabular}{|c|c|c|c|c|c|}
\hline $\begin{array}{l}\tilde{ \pm} \\
\stackrel{n}{n} \\
\dot{m}\end{array}$ & $\begin{array}{l}\hat{n} \\
\dot{m}\end{array}$ & $\begin{array}{l}\stackrel{3}{\sim} \\
\infty \\
\dot{\sim}\end{array}$ & $\begin{array}{r}\hat{N} \\
\dot{n}\end{array}$ & $\stackrel{\tilde{N}}{\tilde{m}}$ & $\begin{array}{l}\stackrel{0}{1} \\
\stackrel{0}{0} \\
\dot{0}\end{array}$ \\
\hline 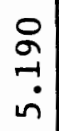 & $\begin{array}{l}\hat{\tilde{N}} \\
\stackrel{y}{v}\end{array}$ & $\begin{array}{l}m \\
\infty \\
\infty \\
\text { in }\end{array}$ & 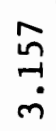 & $\begin{array}{l}\hat{\sigma} \\
\infty \\
\dot{m} \\
\dot{m}\end{array}$ & $\overrightarrow{\tilde{w}}$ \\
\hline $\begin{array}{l}\underset{\sim}{\sim} \\
\dot{\sim}\end{array}$ & $\underset{\sim}{\tilde{N}}$ & $\begin{array}{l}\underset{7}{7} \\
\underset{v}{\sigma}\end{array}$ & $\begin{array}{l}\tilde{\sigma} \\
\dot{v} \\
\dot{v}\end{array}$ & $\begin{array}{l}\text { ๙ু } \\
\text { ণे }\end{array}$ & $\begin{array}{l}\text { 을 } \\
\text { m } \\
\text { nn }\end{array}$ \\
\hline $\begin{array}{l}\text { In } \\
\stackrel{f}{\checkmark} \\
\dot{0}\end{array}$ & $\begin{array}{l}\hat{-1} \\
\dot{0} \\
\text { in }\end{array}$ & $\begin{array}{r}\tilde{\sigma} \\
\text { ñ }\end{array}$ & 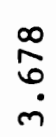 & $\underset{\hat{N}}{\hat{v}}$ & $\begin{array}{l}8 \\
\text { ?. }\end{array}$ \\
\hline $\begin{array}{l}\text { مे } \\
\text { กे }\end{array}$ & 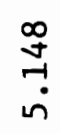 & $\begin{array}{l}m \\
\vec{b} \\
\dot{v}\end{array}$ & $\begin{array}{l}\stackrel{\infty}{\sim} \\
\stackrel{\vartheta}{\Psi} \\
\dot{J}\end{array}$ & $\underset{v}{\tilde{v}}$ & 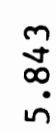 \\
\hline \begin{tabular}{l}
$\infty$ \\
$\infty$ \\
\multirow{v}{*}{} \\
$\dot{n}$ \\
$\dot{n}$
\end{tabular} & $\begin{array}{l}\tilde{N} \\
\stackrel{\sim}{n}\end{array}$ & 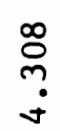 & $\begin{array}{l}\infty \\
\infty \\
\infty \\
\dot{N}\end{array}$ & $\underset{\dot{\sigma}}{\stackrel{n}{\sim}}$ & $\underset{\tilde{\sigma}}{\tilde{\sigma}}$ \\
\hline $\begin{array}{l}\text { जे } \\
\text { ने } \\
\dot{m}\end{array}$ & $\begin{array}{l}\text { 尺 } \\
\text { ñ } \\
\dot{n}\end{array}$ & $\begin{array}{l}\text { i } \\
\infty \\
\dot{\infty}\end{array}$ & 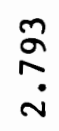 & 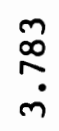 & $\begin{array}{l}\stackrel{\infty}{\infty} \\
\stackrel{\sim}{\sim} \\
\sim\end{array}$ \\
\hline$\underset{\stackrel{N}{N}}{\stackrel{\text { m}}{ }}$ & $\begin{array}{l}\hat{\infty} \\
0 \\
\dot{m}\end{array}$ & $\begin{array}{l}\hat{\sigma} \\
\stackrel{n}{n} \\
\dot{n}\end{array}$ & $\begin{array}{l}\underset{\sim}{\sim} \\
\stackrel{\sim}{\sim}\end{array}$ & $\begin{array}{l}\hat{m} \\
\dot{m} \\
\dot{m}\end{array}$ & 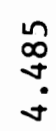 \\
\hline $\begin{array}{l}\stackrel{\infty}{\sim} \\
\stackrel{\sim}{\sim} \\
\dot{m}\end{array}$ & $\begin{array}{l}\infty \\
\overrightarrow{1} \\
\tilde{n} \\
\dot{m}\end{array}$ & $\begin{array}{c}\sim \\
\mathscr{\sim} \\
\stackrel{\sim}{\sim}\end{array}$ & $\begin{array}{l}m \\
\sigma \\
\stackrel{v}{\sim} \\
\dot{\sim}\end{array}$ & $\underset{\sim}{n}$ & $\begin{array}{l}0 \\
\text { 궁 }\end{array}$ \\
\hline$\stackrel{9}{1}$ & $\stackrel{\circ}{\sim}$ & 옷 & $\pi$ & $\stackrel{-1}{\pi}$ & 穴 \\
\hline$\widehat{\sigma}$ & $\mathscr{\infty}$ & â & $\stackrel{0}{\sim}$ & $\stackrel{-1}{\sim}$ & $\stackrel{N}{N}$ \\
\hline
\end{tabular}




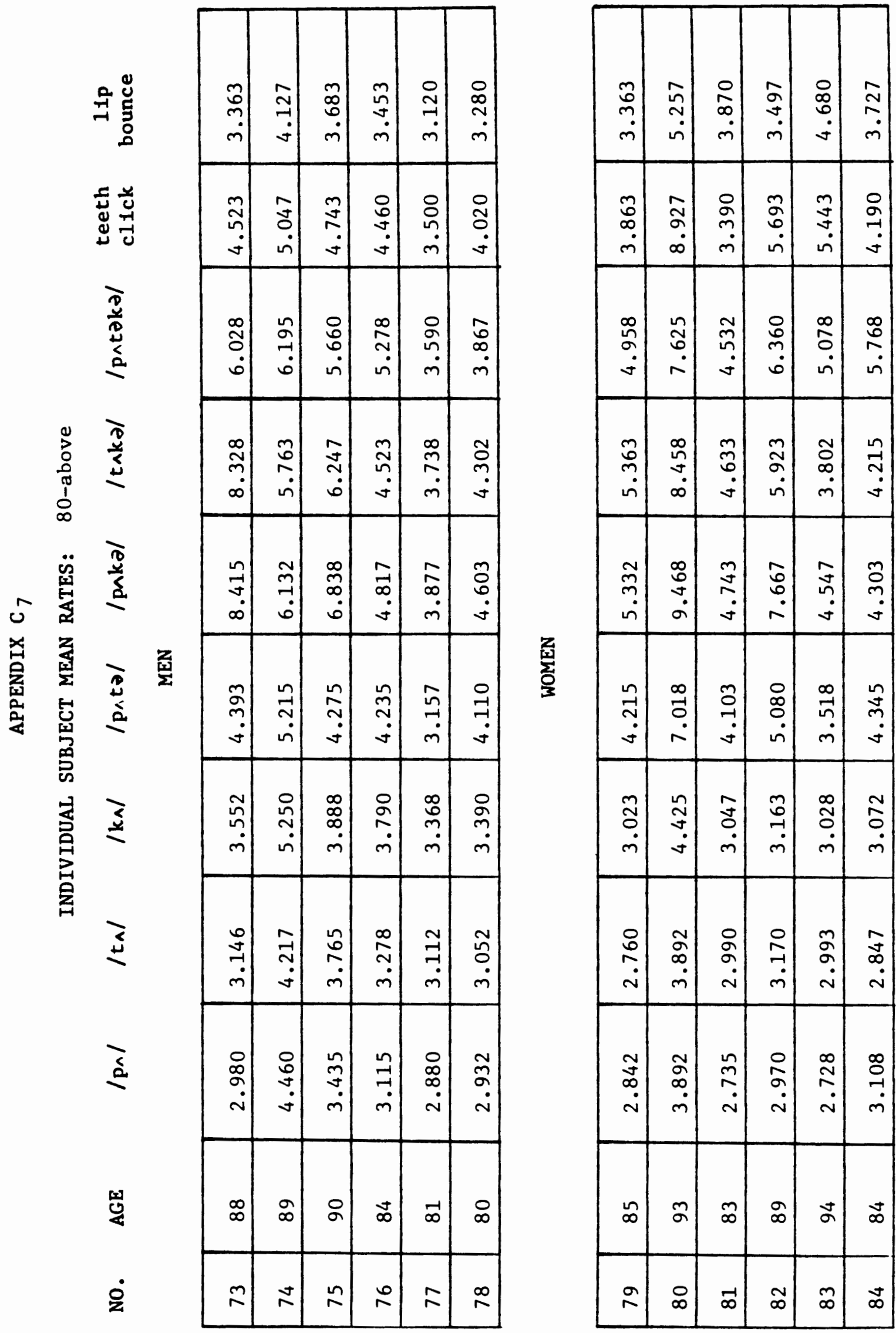

